\title{
Green road-rail intermodal routing problem with improved pickup and delivery services integrating truck departure time planning under uncertainty: an interactive fuzzy programming approach
}

\author{
Yan Sun ${ }^{1}$ D $\cdot$ Nan $\mathrm{Yu}^{2} \cdot$ Baoliang Huang ${ }^{3}$
}

Received: 11 August 2021 / Accepted: 26 November 2021 / Published online: 23 December 2021

(c) The Author(s) 2021

\begin{abstract}
This paper addresses the multi-objective optimization for the road-rail intermodal routing problem that aims to minimize the total costs and carbon dioxide emissions of the routes. To achieve high timeliness of the entire transportation process, pickup and delivery services are simultaneously improved based on the employment of fuzzy soft time windows to measure their service levels. The modeling of road-rail intermodal routing considers fixed schedules of rail and time flexibility of road to match the real-world transportation scenario, in which travel times and carbon dioxide emission factors of road services are considered to be time-varying. To improve the feasibility of the routing, uncertainty of travel times and carbon dioxide emission factors of road services and capacities of rail services are incorporated into the problem. By applying trapezoidal fuzzy numbers to formulate the uncertainty, we propose a fuzzy multi-objective nonlinear optimization model for the routing problem that integrates the truck departure time planning for road services. After processing the model with fuzzy chance-constrained programming and linearization, we obtain an auxiliary equivalent crisp linear model and solve it by designing an interactive fuzzy programming approach with the Bounded Objective Function method. Based on an empirical case study, we demonstrate the validity of the proposed approach and discuss the effects of improving the confidence levels and service levels on the optimization results. The case analysis reveals several managerial insights that help to realize an efficient transportation organization by making effective trade-offs among lowering costs, reducing emissions, improving service levels, and enhancing feasibility.
\end{abstract}

Keywords Green routing · Road-rail intermodal transportation - Service level · Carbon dioxide emissions · Truck departure time planning $\cdot$ Uncertainty $\cdot$ Multi-objective optimization $\cdot$ Interactive fuzzy programming

\section{Introduction}

Yan Sun

sunyanbjtu@163.com

$凶 \mathrm{Nan} \mathrm{Yu}$

yunan@wti.ac.cn

Baoliang Huang

huangbaoliang70@126.com

1 School of Management Science and Engineering, Shandong University of Finance and Economics, Jinan 250014, Shandong Province, China

2 China Waterborne Transport Research Institute, Beijing 100088, China

3 School of International Trade and Economics, Shandong University of Finance and Economics, Jinan 250014, Shandong Province, China
Intermodal transportation uses at least two transportation modes (e.g., water, air, road, and rail) in a transportation chain to distribute goods within the same loading unit (usually a twenty-foot equivalent unit (TEU) container) from origins to destinations [1,2]. By combining the advantages of various transportation modes, intermodal transportation can achieve higher economic benefits, greater environmental sustainability, and improved time efficiency compared with traditional unimodal transportation [3, 4]. Specifically, road-rail intermodal transportation uses container trucks as road services and container block trains as rail services to transport TEU containers, in which the mobility and flexibility of road and the economics of scale of rail can be integrated [5]. Currently, road-rail intermodal transportation plays a crucial role in 
the freight industry, especially in Northern America [5] and Eurasian trans-continental land transportation corridors [6].

Network planning provides solid decision support for the efficient operations and management of the transportation system [7]. There are various optimization problems in intermodal transportation network planning, e.g., terminal network design, intermodal services network design, and intermodal routing. In these research topics, intermodal routing is not fully studied [8]. However, using quantitative models, intermodal routing can optimally utilize the limited transportation resources in the intermodal transportation system to realize the transportation of containers, and further improve the cost-, time-, environment-, and reliability-related performances of the entire transportation system. Therefore, intermodal routing is acknowledged to be a key work to network planning [9]. This study hence investigates the road-rail intermodal routing problem.

Applied in long-distance transportation settings, intermodal transportation is costly. The costs related to transportation activities account for about $30-50 \%$ of the total production cost of a company [10]. As indicated by Flodén et al. [11], the cost is the most important factor influencing the transportation service selection. Consequently, improving the transportation economy is the principal target of intermodal routing. The intermodal routing models proposed in the majority of the studies thus take the minimization of costs as their optimization objective. There are quite a few studies without considering the economic objective, e.g., Heinold and Meisel [4] take the minimization of transportation time and carbon dioxide emissions as the objectives of the intermodal routing model.

Meanwhile, the transportation industry accounts for more than $30 \%$ of the carbon dioxide emissions in 2018 and is one of the biggest contributors $[12,13]$. Therefore, developing green transportation has been paid great attention by both industry and government, and has become a spotlight in transportation planning [14]. Intermodal transportation is demonstrated to be more environmentally friendly and emits less carbon dioxide than unimodal transportation. But its potential in this concern can be further motivated by incorporating the carbon dioxide emission reduction into the intermodal routing [15]. At the same time being costly and environmentally influential, intermodal transportation is also time-consuming. Timeliness is also an important aspect of intermodal transportation planning. Nowadays, increasing customers seek on-time transportation to take advantage of just-in-time strategy to reduce inventory. Timeliness of intermodal routing should be optimized to improve the service level of transportation to meet customers' demand in this regard [16].

Road-rail intermodal routing is oriented on a complex transportation system. Unlike routing problems in the unimodal transportation system, e.g., vehicle routing problems, road-rail intermodal routing focuses on two different kinds of transportation modes. The operations of rail services follow fixed schedules, while road services are a flexible mode. Schedules should be included in the intermodal routing modeling to make it applicable in practice [8]. Compared with rail services, the operations of road services are flexible, which means that the truck departure times of road services are adjustable. Such flexibility enables the truck departure time planning for road services to be feasible. Meanwhile, there is no capacity limitation on the use of road services, since the trucks are easy to be rented or assigned to carry containers [17].

However, road services are significantly affected by the background traffic conditions where congestion, bad weather, accidents, and other factors may occur [18, 19]. Therefore, the states of road services are unstable and change frequently in different periods of the planning horizon, which makes their travel times and carbon dioxide emissions both time-varying and uncertain. On the contrary, the schedules make rail services operate in a stable environment, which enables the rail services to have considerably deterministic travel times and carbon dioxide emissions. Rail services serve more than the transportation orders that need routing optimization. Many other transportation tasks falling out of the routing optimization object will occupy the rail capacities. It is impossible to predicate all these tasks exactly during the routing optimization conducted before the beginning of the actual transportation, since they may emerge suddenly or randomly [20]. Moreover, natural disasters and man-made faults will also disrupt rail services and degrade their capacities [21]. Therefore, capacities of rail services cannot be known exactly and are uncertain. Both overestimation and underestimation on deterministic capacities will considerably reduce the feasibility of the routing optimization, which has been demonstrated by Sun et al. [20]. Although combining multiple sources of uncertainty (e.g., time uncertainty and capacity uncertainty) may lead to the routing optimization that yields higher feasibility, Delbart et al. [23] indicated that intermodal transportation planning under uncertainty is a research topic still having great potential to investigate.

Under the background introduced above, this study continues to explore the road-rail intermodal routing problem from a multi-objective optimization view that comprehensively consider to improve the environmental sustainability and timeliness of the road-rail intermodal transportation and enhance the feasibility of the routing optimization. Moreover, we formulate the problem based on the modeling of a road-rail intermodal transportation system that matches the real-world transportation practice. To achieve above research targets, we focus on making the following contributions.

(1) A multi-objective optimization for the green routing is conducted. Carbon dioxide emission factors of road 
services are formulated as a parameter that varies in different periods of the planning horizon and is also considered to be uncertain.

(2) Service levels of both pickups and deliveries are modeled based on fuzzy soft time windows and optimized to meet the timeliness of the transportation required by both shippers and receivers.

(3) Travel times of road services are modeled as a timevarying and uncertain parameter. This uncertainty and capacity uncertainty of rail services are combined in the routing problem to improve the feasibility of the optimization and are addressed by fuzzy set theory and fuzzy programming.

(4) Truck departure time planning for road services is incorporated into the road-rail intermodal routing problem considering its potential in making trade-offs among lowering in-transit inventory costs, reducing carbon dioxide emissions, and improving service levels.

The remaining sections of this study are organized as follows. In "Literature review", we conduct a literature review, in which the research gaps are discussed and the research works of this study are presented. In "Problem description", the road-rail intermodal routing problem is described in detail. How to model the service levels, construct the transportation systems, and formulate uncertainty are introduced in this section as background information. In "Model formulation", by formulating fuzzy parameters and resulting fuzzy variables as trapezoidal fuzzy numbers, we propose a fuzzy multi-objective nonlinear optimization model. In "Processing of the proposed FMOMINLP model", we use fuzzy chance-constrained programming and linearization method to process the proposed model to generate its equivalent crisp linear reformulation. After processing, we design an interactive fuzzy programming approach with the Bounded Objective Function method in "Interactive fuzzy programming approach" to obtain the Pareto solutions to the problem. In "Empirical case study", an empirical case study is presented to demonstrate the validity of the proposed approach and provide managerial insights based on the computational results to help decision-makers to better organize the transportation. Finally, the conclusions of this study are drawn in "Conclusions".

\section{Literature review}

As indicated in the introduction, this study extends the road-rail intermodal routing problem by considering following aspects: (1) reducing carbon dioxide emissions as an objective, (2) improving the timeliness by optimizing both pickup and delivery services, and (3) modeling a real-world transportation system in which its uncertain and time-varying parameters are fully formulated. Accordingly, the literature review is oriented on above aspects to systematically demonstrate the contributions of this study.

Currently, there are many studies on green intermodal routing. As reviewed by Sun [24], the carbon emission cost (or tax) method is widely employed in the relevant literature to resolve environmental concerns when modeling intermodal routing. This method converts the carbon dioxide emissions into the costs and includes them in the objective of minimizing the total costs. This method is utilized by Guo et al. [25] in optimizing an international intermodal routing problem under travel time stochasticity, by Zhang et al. [26] in modeling a multimodal transportation problem with environmental concerns and time windows, and by Wang et al. [27] in addressing an intermodal scheduling problem with seaborne arrival uncertainty. Chang et al. [28] formulate the carbon dioxide emissions as the external cost of transportation and explore the shortest sea-truck intermodal route problem oriented on the South Korean case.

However, carbon emission cost (or tax) method does not work well in all cases. Sun et al. [22] point out that relatively high emission cost/tax rates that are not applicable in practice are needed for some intermodal routing cases if using this method. As an alternative, multi-objective optimization with environmental objective has been employed by some articles and shows good feasibility to provide solutions that can compromise the costs and emissions of the intermodal routes. This method can be found in Heinold and Meisel's study [3] on intermodal routing with emission limits and emission allocation schemes, in Vale and Ribeiro's research [29] on multi-objective optimization for sustainable intermodal routing, and in Demir et al. [15] that propose bi-objective modeling and analysis for the green intermodal transportation.

In the existing literature, researchers mainly concern the timeliness of deliveries in intermodal transportation. Many studies use lead time or due date to avoid the delay of goods deliveries to the destinations. Uddin and Huynh [21] formulate that the total transportation period of a freight flow from the origin to the destination through the planned route should not exceed an upper bound. To plan the hazardous materials transportation, Verma and Verter [30] model a truck-rail intermodal routing with a lead time constraint. This method can also be found in Sun and Lang's work [31] on modeling a multimodal routing with schedule-based services, and in Demir et al.'s study [32] on a green intermodal transportation problem that formulates the travel time uncertainty. However, this method can only avoid the delayed deliveries, while tolerates the early deliveries that may be not accepted by customers.

To fix this issue, a few relevant studies adopt time windows to enhance the on-time deliveries. Penalty costs are caused by the deliveries whose accomplished times fall out of the 
time window, which can be seen in Fazayeli et al. [33] where a multimodal location-routing problem with fuzzy demands is discussed and in Sun [9] who proposes an intermodal routing model with demand and capacity fuzziness. While others consider that time windows must be exactly satisfied by the intermodal routing. Zhao et al. [34] propose a hard constraint to regulate that the deliveries of containers using the intermodal routes must be accomplished within the time windows.

When establishing the intermodal transportation system, the schedules of some transportation modes are modeled as fixed departure times $[24,25,35,36]$ or scheduled service time windows at nodes $[10,17,33]$. However, compared with these works, the authors' previous study [9] has fully studied the schedules of rail services that include loading and unloading operation time windows, departure times, arrival times, operation routes, and operation periods. Consequently, the modeling of rail services can refer to this paper. Therefore, this study turns attention to the modeling of road services considering the time variation and uncertainty of their travel times and carbon dioxide emissions.

In the existing literature, uncertainty and time variation of road travel times are considered by limited studies. By assuming that the uncertainty of travel times and transfer times follows some common random distributions, Zhao et al. [34] model a stochastic sea-rail intermodal routing problem with time windows. Demir et al. [32] and Hrušovský et al. [35] formulate travel time stochasticity and establish a stochastic intermodal routing model to find the possible disruptions and modify unreliable routes. Travel time stochasticity can also be found in Guo et al.'s paper [25] that addresses a dynamic intermodal routing problem using stochastic and robust programming approaches.

Under a deterministic environment, Sun et al. [22] and Guo et al. [37] consider the time-dependent travel times of road services and employ piecewise linear functions to express this characteristic. The former integrates this characteristic into a green multimodal routing problem in a fuzzy environment. The latter formulates a dynamic routing problem in the hinterland synchromodal transportation. As for the formulation of carbon dioxide emissions, only Ziaei and Jabbarzadeh [38] model the uncertainty of carbon dioxide emission factors using interval fuzzy numbers in a green multimodal location-routing problem based on a multi-objective robust fuzzy optimization approach.

Compared to travel time uncertainty, capacity uncertainty received less attention from existing literature on intermodal routing. The authors' previous studies $[9,20,22]$ discuss this issue using fuzzy numbers to represent the uncertain capacities and establishing fuzzy optimization models. Instead of using fuzzy programming, Uddin and Huynh [21] formulate stochastic capacities to achieve reliable solutions to the road-rail intermodal routing problem.
Above all, the existing literature has achieved a solid foundation for the intermodal routing problem. But research gaps still exist as follows:

(1) Although the existing literature has acknowledged the multi-objective optimization to be an effective method to deal with green intermodal routing problem, none of them consider both the time variation and uncertainty of the carbon dioxide emission factors of transportation services when modeling the environmental objective.

(2) Although the existing literature has paid attention to the timeliness of the intermodal transportation, they only focus on improving the service levels of deliveries. However, the timeliness of intermodal transportation is not only related to delivery services but also influenced by pickup services [39]. In other words, the two services are equally important for achieving on-time transportation.

(3) Although better than the use of lead time or due date, time windows show some limitations. As for soft time windows, penalties may not be created immediately when a time window is violated, and the loss caused by the violation may be in the long term [40]. Moreover, it is difficult to determine a reasonable penalty cost rate in practice. As for hard time windows, it becomes too strict and less flexible when the customers accept early or delayed pickup or delivery services to a certain degree, and may lose some solutions that meet the customers' tolerance.

(4) The existing literature only considers the time variation and uncertainty of travel times and carbon dioxide emissions of road services separately. The combination of both travel time uncertainty and capacity uncertainty is also neglected by the existing studies. Furthermore, it is difficult to collect enough priori data to fit the probability distribution in most cases. The feasibility of stochastic programming in modeling intermodal routing under uncertainty is considerably restricted [33, 41, 42].

(5) Without considering the time variation of the travel times and carbon dioxide emission factors of road services, the existing articles cannot formulate the truck departure time planning that may contributes to lowering costs, reducing carbon dioxide emission and improving timeliness of the road-rail intermodal routing.

To bridge these research gaps and achieve the contributions claimed in "Introduction", we conduct the following works to address the road-rail intermodal routing problem.

(1) We consider the improvement on the timeliness of transportation from both pickup and delivery services. We utilize fuzzy soft time windows, a widely used form in 
vehicle routing problems [40, 43], to measure and optimize the service levels of pickups and deliveries to meet customers' subjective satisfaction on the timeliness of transportation.

(2) We formulate the time variation of both travel times and carbon dioxide emission factors of road services in different periods of the planning horizon using a piecewise linear function. The truck departure time planning for road services based on the time-varying travel times and carbon dioxide emissions is included in the routing problem.

(3) Based on fuzzy set theory, we model the uncertainty of both travel times and carbon dioxide emission factors of road services as well as the capacity uncertainty of rail services using trapezoidal fuzzy numbers.

(4) We develop an interactive fuzzy programming approach for the multi-objective road-rail intermodal routing problem that comprehensively combines above considerations.

\section{Problem description}

This section systematically describes the background information on the specific road-rail intermodal routing problem to make the entire problem easy to understand.

\section{Modeling pickup and delivery service levels}

In this study, we consider the improvement on the service levels of both pickups and deliveries to enhance the timeliness of the entire transportation process. The transportation of the containers of a transportation order starts at the pickup start time at the origin (i.e., the time when the containers start to be picked up by road service at the origin). It ends at the delivery accomplished time at the destination (i.e., the time when the containers arrive at the destination and get loaded from the trucks). Therefore, the pickup service levels are determined by the service start times, while the delivery service levels are decided by the service accomplishment times.

As explained in "Literature review", a fuzzy soft time window $\left[t_{1}, t_{2}, t_{3}, t_{4}\right]$ is applied to measure the service level. $\left[t_{2}, t_{3}\right]$ is the favorite time window of a shipper or receiver, and the service level reaches up to 1 when the time indicating the start or end of transportation falls into this range. $t_{1}$ and $t_{4}$ are the acceptable earliest and latest time claimed by the shipper or receiver, and the service level is less than 1 when such a time falls into range $\left[t_{1}, t_{2}\right]$ or $\left[t_{3}, t_{4}\right]$. When the time increases to $t_{4}$ or decreases to $t_{1}$, the service level will gradually reduce to 0 . Accordingly, we use Eq. (1) to measure the service levels of the entire transportation process [40].

$$
\omega(t)=\left\{\begin{array}{ccc}
0 & \text { if } & t<t_{1} \\
\frac{t-t_{1}}{t_{2}-t_{1}}, & \text { if } & t_{1} \leq t<t_{2} \\
1 & \text { if } & t_{2} \leq t \leq t_{3} \\
\frac{t_{4}-t}{t_{4}-t_{3}}, & \text { if } & t_{3}<t<t_{4} \\
0 & \text { if } & t \geq t_{4}
\end{array}\right.
$$

Suppose $\left[t_{1}, t_{2}, t_{3}, t_{4}\right]$ is a pickup time window and the minimum pickup service level accepted by the shipper is $\alpha$ where $\alpha \in[0,1]$ (see Fig. 1). Based on Eq. (1), $\omega(t)=$ $\frac{t-t_{1}}{t_{2}-t_{1}} \geq \alpha$ determines the lower bound of $t$ that is $t_{1}+\alpha$ $\left(t_{2}-t_{1}\right)$, and $\omega(t)=\frac{t_{4}-t}{t_{4}-t_{3}} \geq \alpha$ sets its upper bound that is $t_{4}-\alpha\left(t_{4}-t_{3}\right)$. Accordingly, there is Eq. (2) to ensure that $\omega$ $(t) \geq \alpha$.

$\omega(t) \geq \alpha \Leftrightarrow\left\{\begin{array}{l}t \leq t_{4}-\alpha\left(t_{4}-t_{3}\right) \\ t \geq t_{1}+\alpha\left(t_{2}-t_{1}\right)\end{array}\right.$

Based on the planned the pickup start time at the origin and road-rail intermodal route, the delivery of the containers of a transportation order to the destination should also be accomplished within a specific time range that meets the minimum delivery service level accepted by the receiver, which is illustrated by a delivery time window $\left[t_{1}^{\prime}, t_{2}^{\prime}, t_{3}^{\prime}, t_{4}^{\prime}\right]$ and a minimum delivery service level $\alpha^{\prime}$ in Fig. 1 .

\section{Modeling transportation system}

The routing problem always follows a specific transportation system. Transportation infrastructures and services distributed in the system are the foundation for routing goods from origins to destinations. Therefore, to solve the problem, the first work is to determine a transportation system. To understand the road-rail intermodal transportation system, we first formulate its network structure. Then, the two transportation services are modeled based on their respective operational characteristics. Based on the above aspects, we can present a transportation process that can coordinate road and rail services in the routing modeling.

\section{Modeling transportation network structure}

In the practice, the hub-and-spoke network is most suitable for the road-rail intermodal transportation [2, 42, 44]. Using origins and destinations as spokes and rail terminals as hubs, the hub-and-spoke network takes full advantage of the good accessibility and mobility of road services (i.e., trucks) to pick up goods from origins to rail terminals and deliver goods from rail terminals to destination, while uses rail services that are cost-efficient, environmentally friendly, and reliable to provide long-haul transportation between hubs. In the huband-spoke network, transportation process consists of pickup 


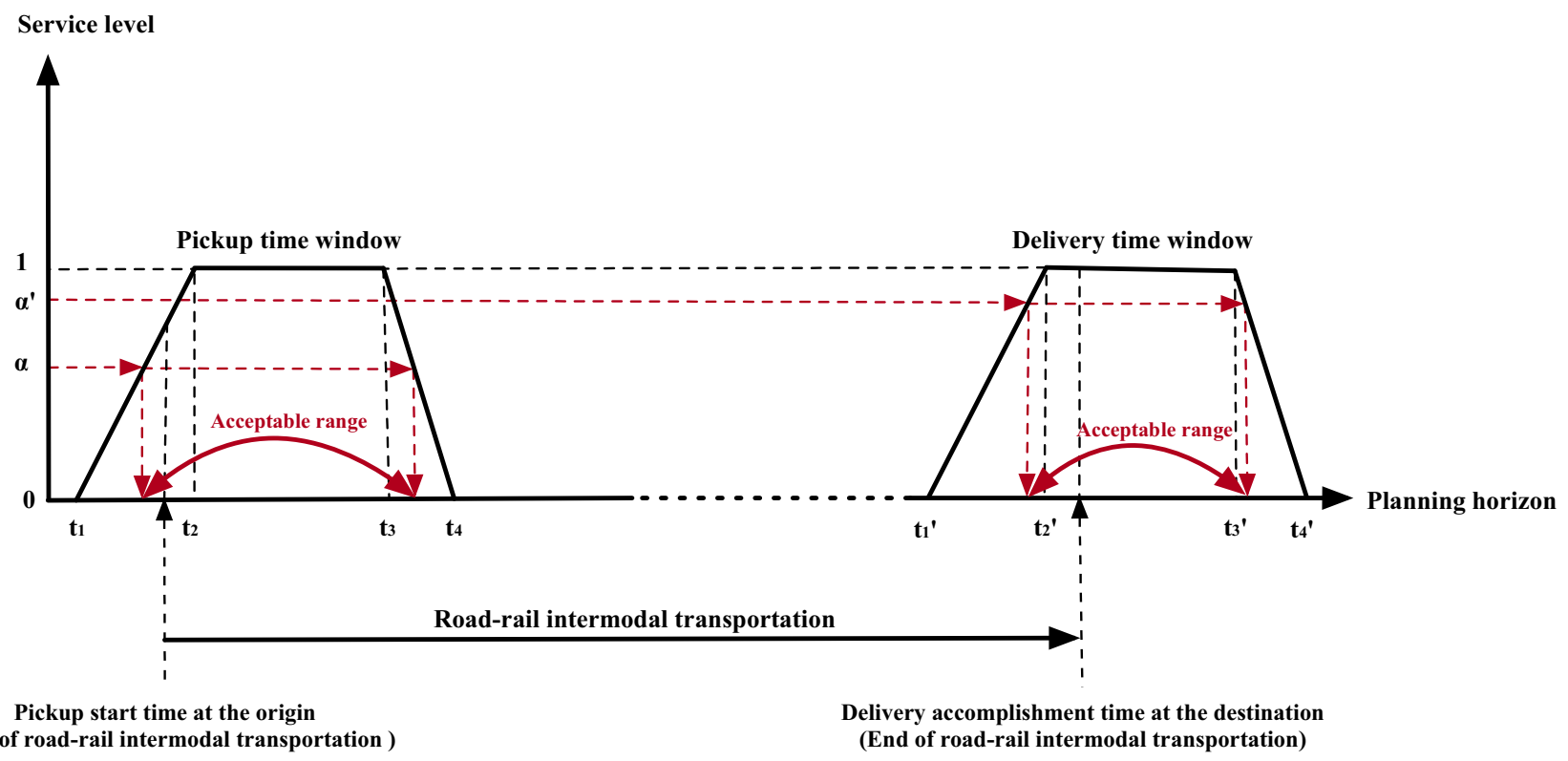

Fig. 1 Service levels of pickups and deliveries

by road (i.e., pre-haul), long-haul by rail, and delivery by road (i.e., end-haul). Economies of scale can be achieved at the hubs through pickup and delivery services.

Moreover, intermodal transportation is more timeconsuming than road transportation due to the restrictions of fixed rail schedules and transshipments between road and rail. A point-to-point structure of road transportation network that directly connects origins and destinations should be used and thus integrated into the hub-and-spoke network when some transportation orders should be accomplished within short periods [45]. Consequently, we establish a road-rail intermodal transportation network illustrated by Fig. 2. It uses the hub-and-spoke structure as the backbone and the point-to-point structure as the supplement. This kind of transportation system has also been applied in the authors' previous papers [9, 45] and many other studies [21, 46].

\section{Modeling transportation services}

In the transportation practice, the operations of rail services should follow fixed schedules. The schedules regulate the loading and unloading operation time windows, departure times, arrival times, operation routes, and operation periods of rail services. The schedules make rail services operate in a stable environment, which enable the rail services to have deterministic travel times and carbon dioxide emission factors. However, the schedules of rail services restrict the coordination of two transportation modes in the routing. Transshipments between the two transportation modes should be arranged based on the rail schedules strictly. Oth- erwise, the road-rail intermodal routes will be infeasible due to the failure of the transshipments.

Compared with rail services, road services are a timeflexible mode. In most cases, their operations are not restricted by schedules, which enable them to yield flexible truck departure times. However, as claimed in "Introduction", road services are significantly affected by unstable background traffic conditions. Therefore, the travel times and carbon dioxide emissions of road services cannot keep constant in the different periods of the planning horizon. They will increase when the background traffic conditions get worse, while decrease when the conditions become better.

To model the variation of the travel times of road services, the existing literature on the intermodal transportation planning (e.g., Sun et al. [22] and Guo et al. [37]) formulates the time-dependent travel times using piecewise linear functions. This kind of modeling is also very popular in the vehicle routing problems. In such a formulation, the travel time of a road service on a transportation line will increase or decrease linearly, and sometime keep constant in a day, which reflects the variation of the background traffic conditions. However, this study also integrates uncertainty (i.e., fuzziness) into the operations of the road service, and it is impossible to determine the fuzzy travel time and fuzzy carbon dioxide emission factor of a road service in every moment of a day under the time-dependent setting where the two parameters change constantly.

In this condition, to deal with the time variation and uncertainty of the travel times and carbon dioxide emission factors of road services effectively, we first divide the time of a day 


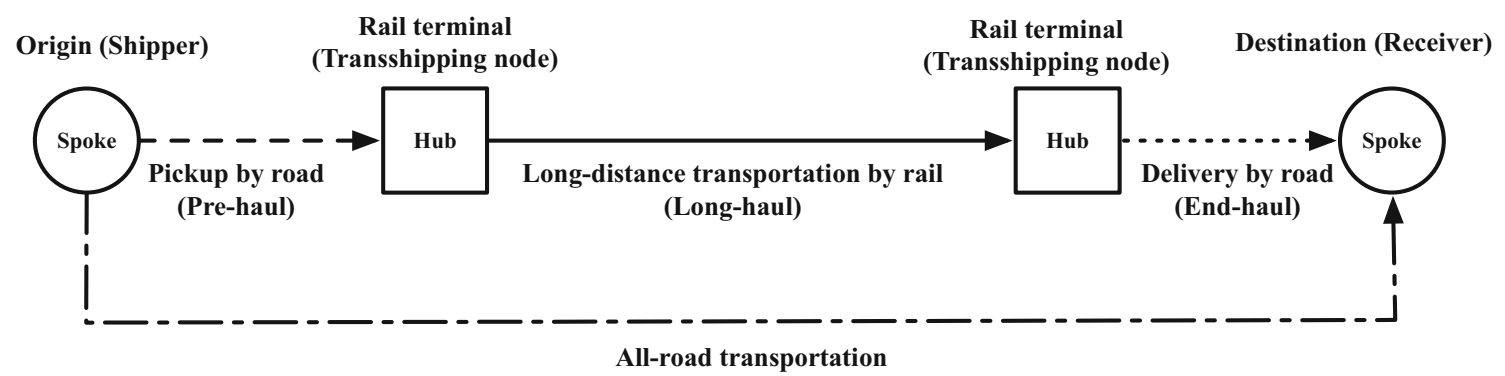

Fig. 2 Road-rail intermodal transportation network

Travel time / Emission factor

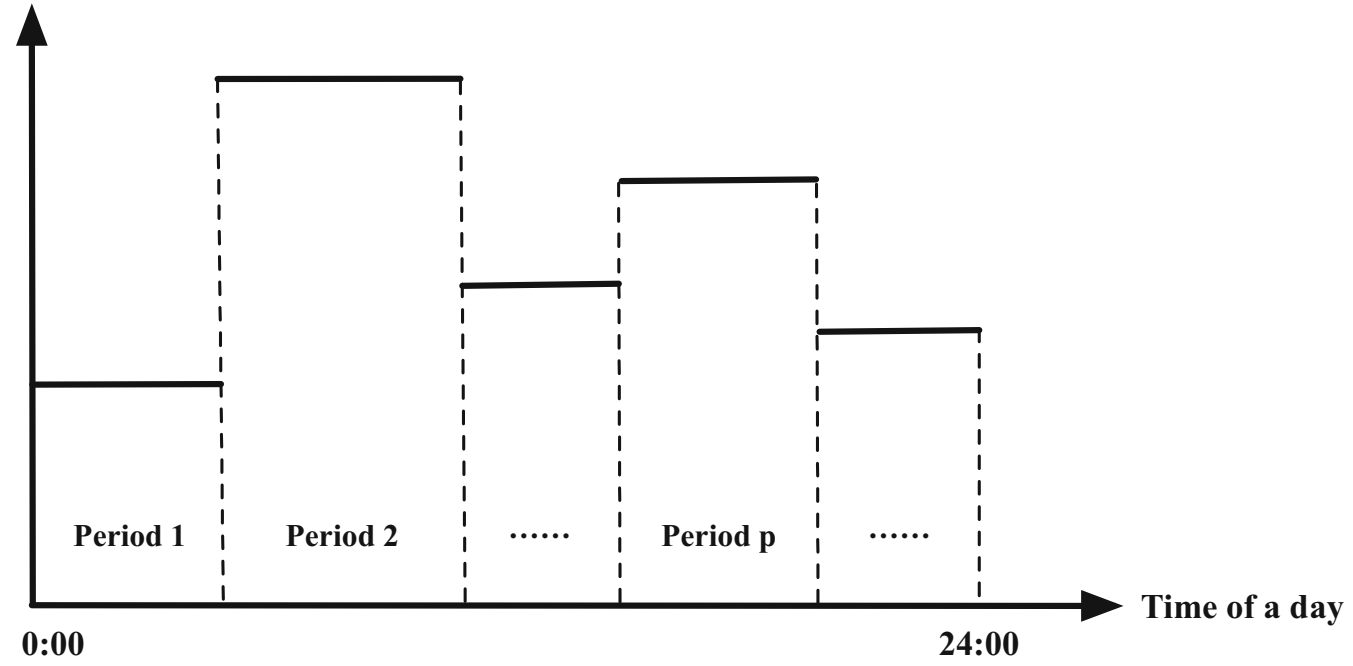

Fig. 3 Time-varying travel times and carbon dioxide emission factors of road service in the deterministic environment

(i.e., 0:00-24:00) into several continuous periods according to the variation of the background traffic conditions. Then, under a deterministic environment, we assume that both the travel times and the carbon dioxide emission factors of a road service within a certain period are constant. As a result, we adopt a specific piecewise linear function illustrated by Fig. 3 to model the time-varying travel times and carbon dioxide emission factors of road services under a deterministic environment. Furthermore, we formulate the fuzziness of both travel time and carbon dioxide emission factor of a road service in every period of a day, which will be explained in "Modeling uncertainty". Based on this modeling, the characteristics of road services' parameters, i.e., time variation and uncertainty, can be fully modeled in the road-rail intermodal routing problem.

As a result, considering the time-varying travel times and carbon dioxide emissions, the departure times of trucks can be planned to achieve the following goals. Therefore, it is necessary to incorporate the truck departure time planning for road services into the road-rail intermodal routing modeling.
(1) Coordinating rail services by following their schedules to ensure that the transshipment from road to rail can be carried out smoothly.

(2) Making trade-offs among reducing in-transit inventory periods related to the costs of transportation, lowering carbon dioxide emissions, and improving service levels of pickups and deliveries.

\section{Modeling transportation process}

The entire transportation process in the hub-and-spoke part of the transportation network can be described as follows by considering the schedules of rail services and flexibility of road services.

\section{Step 1: Pickup by road (Pre-haul)}

- Step 1.1 A pickup start time is planned for the containers of a transportation order by considering: (1) satisfying pickup service level; and (2) balancing the carbon dioxide emissions and the in-transit inventory period at the rail ter- 
Fig. 4 A trapezoidal fuzzy number

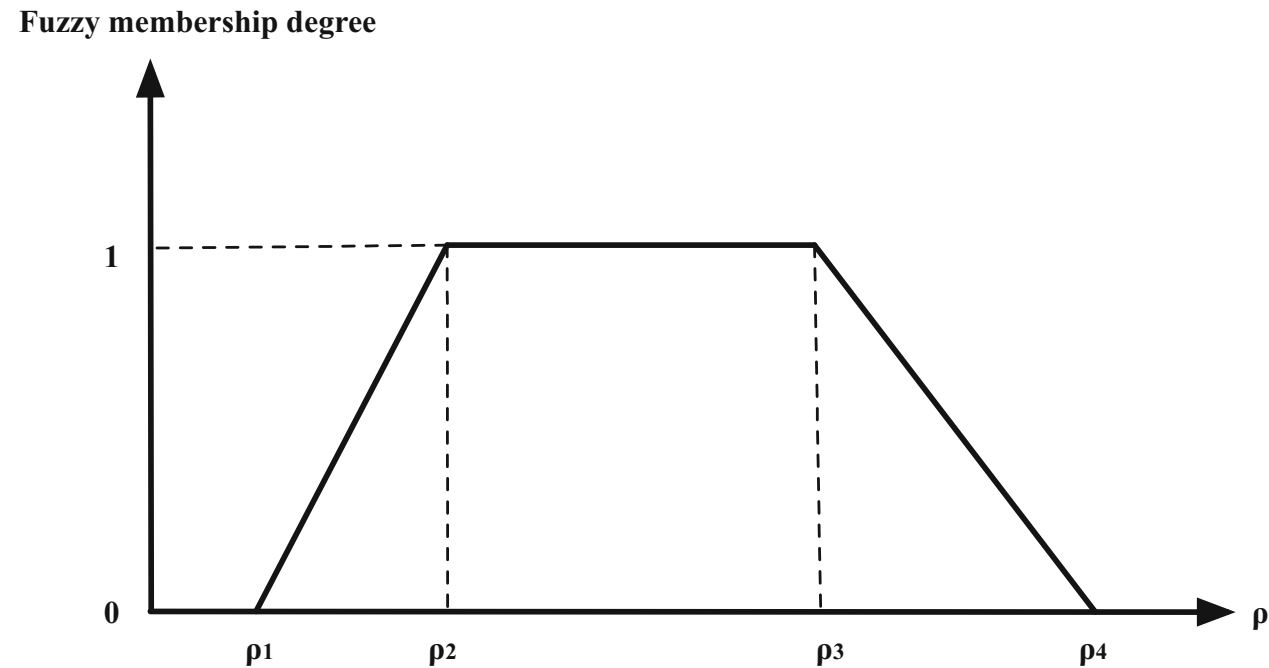

minal. And the containers start to be loaded on the trucks at the pickup start time.

- Step 1.2 After being loaded on the trucks, the containers depart from the origin immediately, and then arrive at the rail terminal by road service. After arriving at the rail terminal, the containers start to be unloaded from trucks immediately.

\section{Step 2: Long-distance transportation by rail (Long-} haul)

- Step 2.1 A rail service (i.e., a container block train) is selected based on a hard constraint that the time when the containers get loaded on it should not be later than its scheduled loading operation cutoff time. Containers should wait if the time when they get unloaded from trucks is earlier than the train's scheduled loading operation start time, which leads to the in-transit inventory period.

- Step 2.2 After the loading is accomplished, containers should wait until the scheduled departure time of the train. The containers depart from the rail terminal along with the train and arrive at the successive terminal at the train's scheduled arrival time.

- Step 2.3 After arrival at the rail terminal, the containers should wait until the scheduled unloading operation start time and then start to be unloaded from the train.

\section{Step 3: Delivery by road (End-haul)}

- Step 3.1 After the unloading is accomplished, the truck departure time is planned for the selected road service by considering: (1) satisfying delivery service level; and (2) balancing the carbon dioxide emissions and the in-transit inventory period at the rail terminal.
- Step 3.2 The containers depart from the rail terminal and arrive at the destination by road service. After arriving at the destination, the containers immediately start to be unloaded from the trucks. The transportation order when the unloading is accomplished.

When an all-road service is selected, the transportation process is simpler. In this case, the containers of a transportation order start to be loaded on the trucks at the pickup start time, then depart from the origin when the loading is accomplished, and finally arrive at the designation and get unloaded from the trucks.

\section{Modeling uncertainty}

We formulate three uncertain parameters as trapezoidal fuzzy numbers, including travel times and carbon emission factors of road services in different periods of the planning horizon and the capacities of rail services. Shown in Fig. 4, a trapezoidal fuzzy number utilizes four prominent points to represent an uncertain parameter [45]. As for a trapezoidal fuzzy number $\tilde{\rho}=\left(\rho_{1}, \rho_{2}, \rho_{3}, \rho_{4}\right)$ :

$\rho_{1}$ is the minimum value estimated by decision-makers. It refers to the best case for road services where they yield minimum travel times and carbon dioxide emission factors under good background traffic conditions. However, it indicates the worst case for rail services where minimum capacities are available for the containers.

Contrary to $\rho_{1}, \rho_{4}$ means the maximum value estimated by decision-makers. It shows the worst case for road services, in which bad background traffic conditions lead to maximum values of travel times and carbon dioxide emissions. While it represents the best case for rail services, in which their capacities are not occupied and can be fully provided for the routing. 


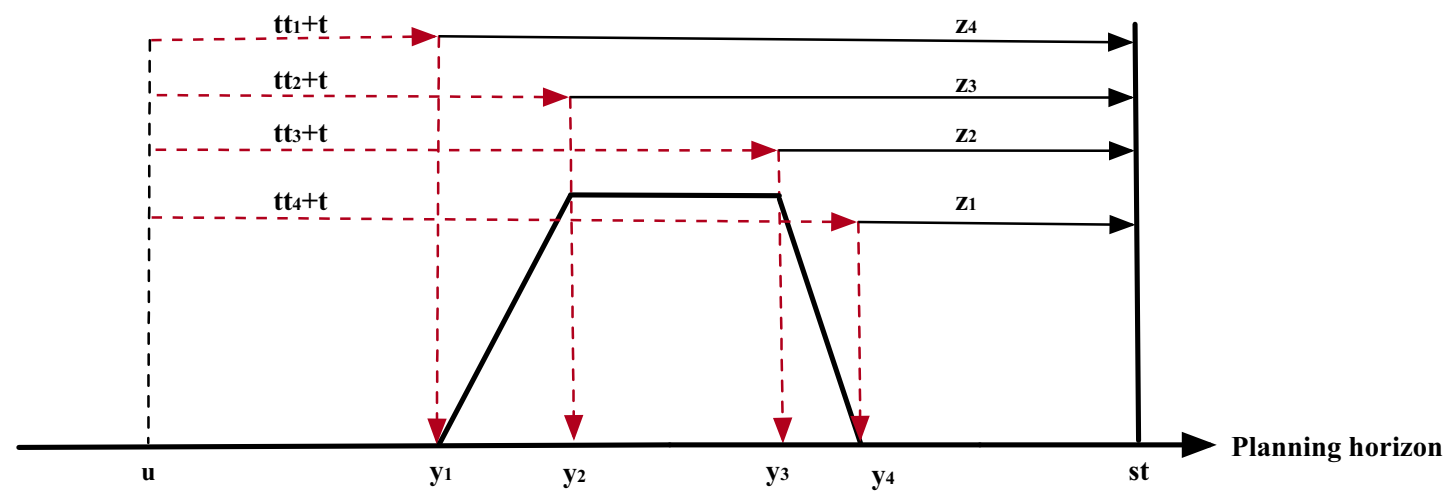

- u: the planned departure time of road service

- ( $\left.t_{1} 1, t_{2}, t t t_{3}, t t t_{4}\right)$ : the fuzzy travel time of road service

- $t$ : the unloading time of the containers from trucks

- $\left(y_{1}, y_{2}, y_{3}, y_{4}\right)$ : the fuzzy time when containers arrive at the rail terminal and get unloaded from trucks

- st: the scheduled operation start time of the train

- $\left(\mathrm{z}_{1}, \mathrm{z}_{2}, \mathrm{zz}_{3}, \mathrm{z}_{4}\right)$ : the fuzzy waiting period of containers at the rail terminal before being loaded on the train

Fig. 5 Resulting trapezoidal fuzzy variables

$\left[\rho_{2}, \rho_{3}\right]$ is the most likely estimation range determined by decision-makers, and gives all the possible values of the three uncertain parameters in most cases. When there is $\rho_{2}=\rho_{3}$, $\tilde{\rho}$ equals to a triangular fuzzy number.

Among the three fuzzy parameters, fuzzy travel times of road services lead to the fuzziness of the two variables, i.e., the times when the containers arrive and get unloaded at the nodes and their waiting periods at the nodes, which is explained by Fig. 5. Figure 5 illustrates that fuzzy waiting period $\tilde{z}=\left(z_{1}, z_{2}, z_{3}, z_{4}\right)$ will move closer to $s t$ when a period with larger fuzzy travel times is selected by the road service. During the moving process, $z_{1}, z_{2}, z_{3}$, and $z_{4}$ will successively decrease to 0 . Finally, $\tilde{z}=(0,0,0,0)$ when $y_{1}$ equals to st. According to the author's previous article [9], $\tilde{z}$ can be determined by $z_{m}=\max \left\{s t-y_{(5-m)}, 0\right\}$ where $m=1,2,3,4$.

Moreover, the problem modeling in a fuzzy environment follows some basic fuzzy arithmetic operations shown as Eqs. (3)-(5) [47]. In these equations, $\rho^{\prime}=\left(\rho_{1}^{\prime}, \rho_{2}^{\prime}, \rho_{3}^{\prime}, \rho_{4}^{\prime}\right)$ is also a trapezoidal fuzzy number and $f$ is a positive deterministic number.

$$
\begin{aligned}
\tilde{\rho}+\tilde{\rho^{\prime}} & =\left(\rho_{1}, \rho_{2}, \rho_{3}, \rho_{4}\right)+\left(\rho_{1}^{\prime}, \rho_{2}^{\prime}, \rho_{3}^{\prime}, \rho_{4}^{\prime}\right) \\
& =\left(\rho_{1}+\rho_{1}^{\prime}, \rho_{2}+\rho_{2}^{\prime}, \rho_{3}+\rho_{3}^{\prime}, \rho_{4}+\rho_{4}^{\prime}\right) \\
\tilde{\rho}-\tilde{\rho^{\prime}} & =\left(\rho_{1}, \rho_{2}, \rho_{3}, \rho_{4}\right)-\left(\rho_{1}^{\prime}, \rho_{2}^{\prime}, \rho_{3}^{\prime}, \rho_{4}^{\prime}\right) \\
& =\left(\rho_{1}-\rho_{4}^{\prime}, \rho_{2}-\rho_{3}^{\prime}, \rho_{3}-\rho_{2}^{\prime}, \rho_{4}-\rho_{1}^{\prime}\right)
\end{aligned}
$$

$f \cdot \tilde{\rho}=f \cdot\left(\rho_{1}, \rho_{2}, \rho_{3}, \rho_{4}\right)=\left(f \cdot \rho_{1}, f \cdot \rho_{2}, f \cdot \rho_{3}, f \cdot \rho_{4}\right)$

\section{Model formulation}

Based on the background information described in "Problem description", we propose a fuzzy multi-objective mixed integer nonlinear programming (FMOMINLP) model to formulate the specific problem investigated in this study. Symbols used to build the FMOMINLP model and their definitions are presented in Table 1.

\section{Optimization objectives}

$$
\begin{aligned}
& \text { Economic objective } \\
& \begin{aligned}
\operatorname{minimize} & \sum_{k \in K} \sum_{(i, j) \in A}\left(\sum_{s \in \Psi_{i j}}\left(c_{1}^{\text {rail }}+c_{2}^{\text {rail }} \cdot d_{i j}^{s}\right) \cdot q_{k} \cdot x_{i j s}^{k}\right. \\
& \left.+\sum_{s \in \Omega_{i j}} c^{\text {road }} \cdot d_{i j}^{s} \cdot q_{k} \cdot x_{i j s}^{k}\right) \\
& +\sum_{k \in K} \sum_{i \in N}\left(\sum_{h \in \Gamma_{i}^{-}} \sum_{r \in S_{h i}} c^{r} \cdot q_{k} \cdot x_{h i r}^{k}+\sum_{j \in \Gamma_{i}^{+}} \sum_{r \in S_{i j}} c^{s} \cdot q_{k} \cdot x_{i j s}^{k}\right) \\
& +\sum_{k \in K} \sum_{(i, j) \in A}\left(\sum_{s \in \Psi_{i j}} c_{3}^{\text {rail }} \cdot q_{k} \cdot \tilde{\delta}_{i j s k}+\sum_{s \in \Omega_{i j}} c_{3}^{\text {rail }} \cdot q_{k} \cdot \varphi_{i j s}^{k}\right)
\end{aligned}
\end{aligned}
$$

Equation (6) is the economic objective that aims to minimize the total costs for accomplishing all the transportation orders. Equation (6) includes three items. The first item is the travel costs for transporting containers along the directed 
Table 1 Notations

\begin{tabular}{|c|c|}
\hline Sets, indices, and parameters & Definitions \\
\hline \multicolumn{2}{|c|}{ Symbols representing transportation orders } \\
\hline$K$ & Set of transportation orders \\
\hline$k$ & Index of a transportation order, and $k \in K$ \\
\hline$\tau_{k}$ & Index of the origin of transportation order $k$ \\
\hline$\epsilon_{k}$ & Index of the destination of transportation order $k$ \\
\hline$q_{k}$ & Volume in twenty feet equivalent unit (TEU) of the containers of transportation order $k$ \\
\hline$\left[\pi_{k}^{1}, \pi_{k}^{2}, \pi_{k}^{3}, \pi_{k}^{4}\right]$ & Time window of picking up the containers of transportation order $k$ at the origin \\
\hline$\xi_{k}$ & Minimum pickup service level accepted by the shipper of transportation order $k$, and $\xi_{k} \in[0,1]$ \\
\hline$\left[\eta_{k}^{1}, \eta_{k}^{2}, \eta_{k}^{3}, \eta_{k}^{4}\right]$ & Time window of delivering the containers of transportation order $k$ at the destination \\
\hline$\varpi_{k}$ & Minimum delivery service level accepted by the receiver of transportation order $k$, and $\varpi_{k} \in[0,1]$ \\
\hline \multicolumn{2}{|c|}{ Symbols representing road-rail intermodal transportation network } \\
\hline$N$ & Set of the nodes in the network \\
\hline$h, i, j$ & Indices of nodes in the network, and $h, i, j \in N$ \\
\hline$\Gamma_{i}^{-}$ & Set of the predecessor nodes to node $i$, and $\Gamma_{i}^{-} \subseteq N$ \\
\hline$\Gamma_{i}^{+}$ & Set of the successor nodes to node $i$, and $\Gamma_{i}^{+} \subseteq N$ \\
\hline A & Set of directed arcs in the network \\
\hline$(i, j)$ & Directed arc from node $i$ to node $j$ \\
\hline$S$ & Set of transportation services in the network \\
\hline$r, s$ & Indices of transportation services, and $r, s \in S$ \\
\hline$S_{i j}$ & Set of transportation services on arc $(i, j)$, and $S_{i j}=\Psi_{i j} \cup \Omega_{\mathrm{ij}}$ \\
\hline$\Psi_{i j}$ & Set of rail services on directed arc $(i, j)$ \\
\hline$\Omega_{i j}$ & Set of road services on directed arc $(i, j)$. \\
\hline \multicolumn{2}{|c|}{ Symbols representing transportation services } \\
\hline$d_{i j}^{S}$ & Travel distance in $\mathrm{km}$ of transportation service $s$ on directed arc $(i, j)$. \\
\hline$t_{i}^{s}$ & Separate loading and unloading operation time in hour per TEU of transportation service $s$ at node $i$ \\
\hline$\left[l_{i}^{s}, o_{i}^{s}\right]$ & $\begin{array}{l}\text { Scheduled loading and unloading operation time window of rail service } s \text { at node } i \text {, where } l_{i}^{s} \text { is the operation } \\
\text { start time and } o_{i}^{s} \text { is the operation cutoff time }\end{array}$ \\
\hline$\tilde{g}_{i j s}$ & Fuzzy capacity in TEU of rail service $s$ on directed arc $(i, j)$, and $\tilde{g}_{i j s}=\left(g_{i j s}^{1}, g_{i j s}^{2}, g_{i j s}^{3}, g_{i j s}^{4}\right)$ \\
\hline$\theta$ & Free-of-charge inventory period in hour provided by rail services \\
\hline$P_{i j}^{s}$ & Set of the periods for road service $s$ on directed arc $(i, j)$ in the planning horizon \\
\hline$p$ & Index of a period \\
\hline$\left[a_{i j s}^{p}, b_{i j s}^{p}\right]$ & Interval of period $p$ of road service $s$ on directed arc $(i, j)$, and $p \in P_{i j}^{s}$ \\
\hline$\tilde{t}_{i j s p}$ & Fuzzy travel time in hour of road service $s$ on directed arc $(i, j)$ in period $p$, and $\tilde{t}_{i j s p}=\left(t_{i j s p}^{1}, t_{i j s p}^{2}, t_{i j s p}^{3}, t_{i j s p}^{4}\right)$ \\
\hline \multicolumn{2}{|c|}{ Symbols representing carbon dioxide emissions } \\
\hline$\tilde{e}_{i j s p}$ & $\begin{array}{l}\text { Fuzzy emission factor in kg per km per TEU of road service } s \text { on directed arc }(i, j) \text { in period } p \text {, and } \tilde{e}_{i j s p}= \\
\left(e_{i j s p}^{1}, e_{i j s p}^{2}, e_{i j s p}^{3}, e_{i j s p}^{4}\right)\end{array}$ \\
\hline$e_{i j}^{s}$ & Emission factor in $\mathrm{kg}$ per $\mathrm{km}$ per TEU of rail service $s$ on directed arc $(i, j)$ \\
\hline \multicolumn{2}{|l|}{ Symbols representing costs } \\
\hline$c_{1}^{\text {rail }}$ & Travel cost rate in Chinese Yuan $(\mathrm{CNY})$ per TEU of rail services \\
\hline$c_{2}^{\text {rail }}$ & Travel cost rate in CNY per TEU per $\mathrm{km}$ of rail services \\
\hline$c_{3}^{\text {rail }}$ & Inventory cost rate in CNY per TEU per hour at rail terminals \\
\hline
\end{tabular}


Table 1 continued

\begin{tabular}{|c|c|}
\hline Sets, indices, and parameters & Definitions \\
\hline$c^{\text {road }}$ & Travel cost rate in CNY per TEU per km of road services \\
\hline$c^{s}$ & Separate loading and unloading cost rate in CNY per TEU of transportation service $s$ \\
\hline \multicolumn{2}{|c|}{ Symbols representing auxiliary parameters } \\
\hline$L$ & A large enough positive number \\
\hline$m$ & Index of a prominent point of a trapezoidal fuzzy number, and $m \in\{1,2,3,4\}$ \\
\hline \multicolumn{2}{|l|}{ Variables } \\
\hline$x_{i j s}^{k}$ & $\begin{array}{l}0-1 \text { binary decision variable: if the containers of transportation order } k \text { are moved from node } i \text { to node } j \text { by } \\
\text { transportation service } s, x_{i j s}^{k}=1 \text {; otherwise } x_{i j s}^{k}=0\end{array}$ \\
\hline$w_{i j s k}^{p}$ & $\begin{array}{l}0-1 \text { binary decision variable: if the containers of transportation order } k \text { are moved from node } i \text { to node } j \text { by road } \\
\text { service } s \text { in period } p, w_{i j s k}^{p}=1 \text {; otherwise } w_{i j s k}^{p}=0\end{array}$ \\
\hline$u_{i}^{k}$ & $\begin{array}{l}\text { Non-negative deterministic decision variable representing the time when the containers of transportation order } k \\
\text { start to be loaded on road service at node } i \text { before departure }\end{array}$ \\
\hline$v_{k}$ & $\begin{array}{l}\text { Non-negative deterministic decision variable representing the pickup start time of the containers of } \\
\text { transportation order } k \text { at the origin }\end{array}$ \\
\hline$\tilde{y}_{i k}$ & $\begin{array}{l}\text { Non-negative trapezoidal fuzzy variable representing the time when the containers of transportation order } k \\
\text { arrive at node } i \text { by road service and get unloaded, and } \tilde{y}_{i k}=\left(y_{i k}^{1}, y_{i k}^{2}, y_{i k}^{3}, y_{i k}^{4}\right)\end{array}$ \\
\hline$\tilde{z}_{i j s k}$ & $\begin{array}{l}\text { Non-negative trapezoidal fuzzy variable representing the waiting period in hour of the containers of } \\
\text { transportation order } k \text { at node } i \text { before being loaded on rail service } s \text { on directed arc }(i, j) \text {, and } \tilde{z}_{i j s k}= \\
\left(z_{i j s k}^{1}, z_{i j s k}^{2}, z_{i j s k}^{3}, z_{i j s k}^{4}\right)\end{array}$ \\
\hline$\tilde{\delta}_{i j s k}$ & $\begin{array}{l}\text { Non-negative trapezoidal fuzzy variable representing the charged in-transit inventory period in hour of the } \\
\text { containers of transportation order } k \text { at node } i \text { before being loaded on rail service } s \text { on directed arc }(i, j) \text {, and } \\
\tilde{\delta}_{i j s k}=\left(\delta_{i j s k}^{1}, \delta_{i j s k}^{2}, \delta_{i j s k}^{3}, \delta_{i j s k}^{4}\right)\end{array}$ \\
\hline$\varphi_{i j s}^{k}$ & $\begin{array}{l}\text { Non-negative deterministic representing the charged in-transit inventory period in hour of the containers of } \\
\text { transportation order } k \text { at node } i \text { before being loaded on road service } s \text { on directed arc }(i, j)\end{array}$ \\
\hline
\end{tabular}

arcs by rail and road services. The second one refers to the operation costs for container loading and unloading operations at origins, rail terminals, and destinations. The third one represents the in-transit inventory costs for storing containers at rail terminals before they get loaded on trains or trucks.

\section{Environmental objective}

$$
\begin{aligned}
\operatorname{minimize} & \sum_{k \in K} \sum_{(i, j) \in A}\left(\sum_{s \in \Omega_{i j}} \sum_{p \in P_{i j}^{s}} \tilde{e}_{i j s p} \cdot d_{i j}^{s} \cdot q_{k} \cdot w_{i j s k}^{p}\right. \\
& \left.+\sum_{s \in \Psi_{i j}} e_{i j}^{s} \cdot q_{k} \cdot d_{i j}^{s} \cdot x_{i j s}^{k}\right)
\end{aligned}
$$

Equation (7) is the environmental objective showing the minimization of the total carbon dioxide emissions generated in the transportation process. The activity-based method proposed by Liao et al. [48] is adopted to build this objective function, in which the carbon dioxide emissions of transportation services are determined by multiplying their activity intensity and emission factors.

$$
\sum_{h \in \Gamma_{i}^{-}} \sum_{r \in S_{h i}} x_{h i r}^{k}-\sum_{j \in \Gamma_{i}^{+}} \sum_{s \in S_{i j}} x_{i j s}^{k}=\left\{\begin{array}{cc}
-1 & \forall i=\tau_{k} \\
0 & \forall i \in N \backslash\left\{\tau_{k}, \epsilon_{k}\right\} \quad \forall k \in K \\
1 & \forall i=\epsilon_{k}
\end{array}\right.
$$

Equation (8) is the general flow equilibrium constraint that widely exists in the intermodal routing models. It ensures that a route connecting origin, rail terminals as transshipping nodes, and destination by transportation services can be planned for each transportation order.

$$
\sum_{s \in S_{i j}} x_{i j s}^{k} \leq 1 \forall k \in K \forall(i, j) \in A
$$

Equation (9) ensures that no more than one transportation service can be selected to move the containers of a transportation order on a single directed arc. It means that each transportation order is unsplittable in the entire transportation process.

$$
\sum_{p \in P_{i j}^{s}} w_{i j s k}^{p}=x_{i j s}^{k} \forall k \in K \forall(i, j) \in A \forall s \in \Omega_{i j}
$$

Equation (10) ensures that once a road service is selected for a transportation order, only one of its periods should be 
determined to move the containers. Otherwise, none of its periods will be selected if the road service is not considered.

$u_{\tau_{k}}^{k}=v_{k} \forall k \in K$

Equation (11) regulates that the planned loading start time of the containers of a transportation order at the origin is equal to the planned pickup start time.

$u_{i}^{k} \geq \sum_{h \in \Gamma_{i}^{-}} \sum_{r \in \Psi_{h i}}\left(l_{i}^{r}+q_{k} \cdot t_{i}^{r}\right) \cdot x_{h i r}^{k} \quad \forall k \in K \quad \forall i \in \Gamma_{\epsilon_{k}}^{-} \backslash\left\{\tau_{k}\right\}$

Equation (12) is associated with the transshipment of containers from rail to road. It ensures that the planned start time of loading containers of a transportation order on trucks at the rail terminal should be no earlier than the time when these containers get unloaded from the train.

$$
\begin{aligned}
& u_{i}^{k}+q_{k} \cdot t_{i}^{s}-24 \cdot\left\lfloor\frac{u_{i}^{k}+q_{k} \cdot t_{i}^{s}-24}{24}\right\rfloor \geq a_{i j s}^{p}+L \cdot\left(w_{i j s k}^{p}-1\right) \\
& \forall k \in K \quad \forall(i, j) \in A \quad \forall s \in \Omega_{i j} \forall p \in P_{i j}^{s} \\
& u_{i}^{k}+q_{k} \cdot t_{i}^{s}-24 \cdot\left\lfloor\frac{u_{i}^{k}+q_{k} \cdot t_{i}^{s}-24}{24}\right\rfloor \leq b_{i j s}^{p}+L \cdot\left(1-w_{i j s k}^{p}\right) \\
& \forall k \in K \forall(i, j) \in A \quad \forall s \in \Omega_{i j} \forall p \in P_{i j}^{s}
\end{aligned}
$$

Equations (13) and (14) ensures that the departure time of the containers of a transportation order (i.e., $u_{i}^{k}+q_{k} \bullet t_{i}^{s}$ ) should fall into the selected period of the road service after normalizing into interval [0:00, 24:00] that is the period of a day. In these equations, " $\lfloor *\rfloor$ " is the integral floor function whose output is the maximum integer smaller than $*$.

$$
\begin{aligned}
& \left(u_{i}^{k}+q_{k} \cdot t_{i}^{s}+\sum_{p \in P_{i j}^{s}} t_{i j s p}^{m} \cdot w_{i j s k}^{p}+q_{k} \cdot t_{j}^{s}-y_{j k}^{m}\right) \cdot x_{i j s}^{k}=0 \\
& \forall k \in K \forall(i, j) \in A \quad \forall s \in \Omega_{i j} \forall m \in\{1,2,3,4\} \\
& \tilde{y}_{i k}=\left(y_{i k}^{1}, y_{i k}^{2}, y_{i k}^{3}, y_{i k}^{4}\right) \forall k \in K \forall i \in \Gamma_{\tau_{k}}^{+} \bigcup \Gamma_{\epsilon_{k}}^{-} \backslash\left\{\tau_{k}\right\}
\end{aligned}
$$

By computing the four prominent points separately, Eqs. (15) and (16) determine the trapezoidal fuzzy times when the containers of a transportation order arrive at the nodes by road services and get unloaded from them.

$$
\begin{aligned}
& \left(z_{i j s k}^{m}-\max \left\{l_{i}^{s}-y_{i k}^{(5-m)}, 0\right\}\right) \cdot x_{i j s}^{k} \\
& \quad=0 \quad \forall k \in K \quad \forall(i, j) \in A \quad \forall s \in \Psi_{i j} \quad \forall m \in\{1,2,3,4\}
\end{aligned}
$$

$\tilde{z}_{i j s k}=\left(z_{i j s k}^{1}, z_{i j s k}^{2}, z_{i j s k}^{3}, z_{i j s k}^{4}\right)$

$$
\begin{gathered}
\forall k \in K \quad \forall(i, j) \in A \quad \forall s \in \Psi_{i j} \\
\delta_{i j s k}^{m}=\max \left\{z_{i j s k}^{m}-\theta, 0\right\} \quad \forall k \in K \quad \forall(i, j) \in A \\
\forall s \in \Psi_{i j} \quad \forall m \in\{1,2,3,4\} \\
\underset{\delta}{\tilde{\delta}=}=\left(\delta_{i j s k}^{1}, \delta_{i j s k}^{2}, \delta_{i j s k}^{3}, \delta_{i j s k}^{4}\right) \quad \forall k \in K \quad \forall(i, j) \in A \\
\forall s \in \Psi_{i j}
\end{gathered}
$$

Using the same method formulating Eqs. (17) and (18) give the trapezoidal fuzzy waiting periods of the containers of a transportation order before being loaded on the selected rail services. Furthermore, Eqs. (19) and (20) show the computation of the charged in-transit inventory periods that are also a trapezoidal fuzzy variable.

$$
\left(\varphi_{i j s}^{k}-\max \left\{u_{i}^{k}-\sum_{h \in \Gamma_{i}^{-}} \sum_{r \in \Psi_{h i}}\left(l_{i}^{r}+q_{k} \cdot t_{i}^{r}\right) \cdot x_{h i r}^{k}-\theta, 0\right\}\right) \cdot x_{i j s}^{k}=0
$$

$\forall k \in K \quad \forall i \in N \backslash\left\{\tau_{k}\right\} \forall(i, j) \in A \quad \forall s \in \Omega_{i j}$

$\varphi_{i j s}^{k}=0 \forall k \in K \quad \forall i \in\left\{\tau_{k}\right\} \forall(i, j) \in A \quad \forall s \in \Omega_{i j}$

Equation (21) formulate the charged in-transit inventory periods of the containers of a transportation order before being loaded on the selected road services during the transshipment from rail to road. Equation (22) stresses that inventory is not considered at the origins. Instead, the pickup services at origins will be optimized by Eqs. (25) and (26).

$$
\begin{aligned}
\tilde{y}_{i k}+\tilde{z}_{i j s k}+q_{k} \cdot t_{i}^{s} & \leq o_{i}^{k} \cdot x_{i j s}^{k}+L \cdot\left(1-x_{i j s}^{k}\right) \\
& \forall k \in K \quad \forall(i, j) \in A \quad \forall s \in \Psi_{i j}
\end{aligned}
$$

Equation (23) is the scheduled operation time window constraint of rail service. It ensures that the transshipment from road to rail should be accomplished not later than the scheduled operation cutoff time of the selected rail service.

$\sum_{k \in K} q_{k} \cdot x_{i j s}^{k} \leq \tilde{g}_{i j s} \quad \forall(i, j) \in A$

Equation (24) is the capacity constraint of rail services and avoids the case that the loaded containers exceed the capacity of the selected rail service.

$$
\begin{aligned}
& v_{k} \geq \pi_{k}^{1}+\xi_{k} \cdot\left(\pi_{k}^{2}-\pi_{k}^{1}\right) \forall k \in K \\
& v_{k} \leq \pi_{k}^{4}-\xi_{k} \cdot\left(\pi_{k}^{4}-\pi_{k}^{3}\right) \forall k \in K
\end{aligned}
$$

Equations (25) and (26) are the service level constraints for pickups. They ensure that the planned pickup start time 
for the containers of a transportation order should satisfy the service level requested by the shipper.

$$
\begin{aligned}
& \tilde{y}_{\epsilon_{k} k} \geq \eta_{k}^{1}+\varpi_{k} \cdot\left(\eta_{k}^{2}-\eta_{k}^{1}\right) \forall k \in K \\
& \tilde{y}_{\epsilon_{k} k} \leq \eta_{k}^{4}-\varpi_{k} \cdot\left(\eta_{k}^{4}-\eta_{k}^{3}\right) \forall k \in K
\end{aligned}
$$

Similar to Eqs. (25) and (26), Eqs. (27) and (28) refer to the delivery service level constraints. It ensures that the delivery accomplishment time should meet the receiver's satisfaction degree on the delivery service.

$$
\begin{aligned}
x_{i j s}^{k} \in\{0,1\} \forall k \in K \forall(i, j) \in A \forall s \in S_{i j} \\
w_{i j s k}^{p} \in\{0,1\} \forall k \in K \forall(i, j) \in A \quad \forall s \in \Omega_{i j} \forall p \in P_{i j}^{s} \\
y_{i k}^{4} \geq y_{i k}^{3} \geq y_{i k}^{2} \geq y_{i k}^{1} \geq 0 \forall k \in K \forall i \in \Gamma_{\tau_{k}}^{+} \cup \Gamma_{\epsilon_{k}}^{-} \backslash\left\{\tau_{k}\right\} \\
u_{i}^{k} \geq 0 \forall k \in K \forall i \in\left\{\tau_{k}\right\} \bigcup \Gamma_{\epsilon_{k}}^{-} \\
v_{k} \geq 0 \forall k \in K \\
z_{i j s k}^{4} \geq z_{i j s k}^{3} \geq z_{i j s k}^{2} \geq z_{i j s k}^{1} \geq 0 \quad \forall k \in K \quad \forall(i, j) \in A \\
\forall s \in \Psi_{i j} \\
\delta_{i j s k}^{4} \geq \delta_{i j s k}^{3} \geq \delta_{i j s k}^{2} \geq \delta_{i j s k}^{1} \geq 0 \quad \forall k \in K \quad \forall(i, j) \in A \\
\forall s \in \Psi_{i j} \\
\varphi_{i j s}^{k} \geq 0 \forall k \in K \forall(i, j) \in A \forall s \in \Omega_{i j}
\end{aligned}
$$

Equations (29)-(36) are the domain constraints of deterministic variables and fuzzy variables. They ensure that the values of these variables conform to their definitions presented in Table 1.

\section{Processing of the proposed FMOMINLP model}

In this section, we reformulate the FMOMINLP model by defuzzification and linearization to obtain its auxiliary equivalent crisp model that yields a form of multi-objective mixed integer linear programming (MOMINLP). Using the reformulated MOMINLP model, we are able to design an interactive fuzzy solution approach to solve the routing problem.

\section{Model defuzzification to obtain a MOMINLP model}

The proposed FMOMINLP model contains fuzzy parameters and resulting fuzzy variables in objective functions and constraints. Obviously, this model is unsolvable due to the uncertain information [42]. Therefore, model defuzzification must be carried out to find an auxiliary crisp model that is equivalent to the FMOMINLP one. By solving the crisp model, optimum solutions can be obtained and further used to plan the best road-rail intermodal route scheme.

There are various fuzzy programming methods addressing fuzzy optimization problems in different research fields. Among existing methods, the fuzzy chance-constrained programming (FCCP) method that is based on strong mathematical concepts [49] has been widely used in the current literature. In this method, the expected value of a fuzzy number and its credibility can support various forms of fuzzy numbers, e.g., triangular and trapezoidal fuzzy numbers, and enable decision-makers to make an optimum decision with minimum confidence levels in meeting the chance constraints $[50,51]$. Considering the above advantages, this method is employed to realize the defuzzification of the FMOMINLP model.

\section{Defuzzification of the fuzzy objective functions}

To build the FCCP model for the routing problem, we first adopt the fuzzy expected value operator to reformulate the fuzzy objective functions [52]. For a trapezoidal fuzzy number shown as $\tilde{\rho}=\left(\rho_{1}, \rho_{2}, \rho_{3}, \rho_{4}\right)$, its fuzzy expected value is as Eq. (37) [53].

$E V[\tilde{\rho}]=\frac{\rho_{1}+\rho_{2}+\rho_{3}+\rho_{4}}{4}$

Based on Kundu et al. [54], the fuzzy expected value operator is linear. Suppose there is a fuzzy objective function as Eq. (38) where $f$ is a deterministic parameter and $x_{i j}$ denotes deterministic variables. Using the fuzzy expected value operator, its crisp equivalent form can be obtained according to the demonstration of Eq. (39).

$$
\operatorname{minimize} \sum_{i \in I} \sum_{j \in J} f \cdot \tilde{\rho} \cdot x_{i j}
$$

$$
\begin{aligned}
& \operatorname{minimize} \mathrm{EV}\left[\sum_{i \in I} \sum_{j \in J} f \cdot \tilde{\rho} \cdot x_{i j}\right] \\
& =\sum_{i \in I} \sum_{j \in J} f \cdot \operatorname{EV}[\tilde{\rho}] \cdot x_{i j} \\
& =\sum_{i \in I} \sum_{j \in J} f \cdot \frac{\rho_{1}+\rho_{2}+\rho_{3}+\rho_{4}}{4} \cdot x_{i j}
\end{aligned}
$$

Accordingly, the fuzzy items (i.e., fuzzy in-transit inventory costs of rail services and fuzzy carbon dioxide emissions of road services) in the objective functions of the 
FMOMINLP model have following crisp equivalent form based on fuzzy expected value operator:

$$
\begin{aligned}
\mathrm{EV} & {\left[\sum_{k \in K} \sum_{(i, j) \in A} \sum_{s \in \Psi_{i j}} c_{3}^{\mathrm{rail}} \cdot q_{k} \cdot \underset{i j s k}{\tilde{\delta}}\right] } \\
& =\sum_{k \in K} \sum_{(i, j) \in A} \sum_{s \in \Psi_{i j}} c_{3}^{\text {rail }} \cdot q_{k} \cdot \frac{\delta_{i j s k}^{1}+\delta_{i j s k}^{2}+\delta_{i j s k}^{3}+\delta_{i j s k}^{4}}{4}
\end{aligned}
$$

$$
\begin{aligned}
\mathrm{EV} & {\left[\sum_{k \in K} \sum_{(i, j) \in A} \sum_{s \in \Omega_{i j}} \sum_{p \in P_{i j}^{s}} \tilde{e}_{i j s p} \cdot d_{i j}^{s} \cdot q_{k} \cdot w_{i j s k}^{p}\right] } \\
= & \sum_{k \in K} \sum_{(i, j) \in A} \sum_{s \in \Omega_{i j}} \sum_{p \in P_{i j}^{s}} \frac{e_{i j s p}^{1}+e_{i j s p}^{2}+e_{i j s p}^{3}+e_{i j s p}^{4}}{4} \\
& \cdot d_{i j}^{s} \cdot q_{k} \cdot w_{i j s k}^{p}
\end{aligned}
$$

Finally, we can obtain following economic objective Eq. (42) and environmental objective Eq. (43) that minimize the expected values of the costs and emissions of the road-rail intermodal transportation, respectively. Compared with their initial expressions, the two reformulated objective functions are crisp and well-defined.
Currently, three fuzzy measures, i.e., possibility measure defined by Nahmias [55] and necessity and credibility measures developed by Zheng and Liu [56] have been adopted to model fuzzy chance constraints. An overall introduction to the definitions of these measures can be found in many studies on fuzzy optimization problems, e.g., Zarandi et al. [41] and Cao and Lai [57].

According to their definitions, possibility and necessity represent the extreme attitudes of decision-makers. The former refers to the most optimistic situation, while the latter indicates the most pessimistic situation [58]. However, in practical decision-making, decision-makers' attitudes are different and usually vary between the most optimistic and most pessimistic situations. Under this consideration, credibility measure, an average between possibility and necessity, is most suitable for the decision-makers to make a balance between the extreme situations. Furthermore, Zheng and Liu [56] stress that the self-duality of credibility measure ensures that a fuzzy event must hold if its credibility is 1 , and fail if its credibility is 0 . However, possibility and necessity measures are not self-dual. Consequently, credibility denoted by " $\mathrm{Cr}$ " is used to measure the confidence levels of the fuzzy

$$
\begin{aligned}
\operatorname{minimize} & \sum_{k \in K} \sum_{(i, j) \in A}\left(\sum_{s \in \Psi_{i j}}\left(c_{1}^{\mathrm{rail}}+c_{2}^{\mathrm{rail}} \cdot d_{i j}^{s}\right) \cdot q_{k} \cdot x_{i j s}^{k}+\sum_{s \in \Omega_{i j}} c^{\mathrm{road}} \cdot d_{i j}^{s} \cdot q_{k} \cdot x_{i j s}^{k}\right) \\
& +\sum_{k \in K} \sum_{i \in N}\left(\sum_{h \in \Gamma_{i}^{-}} \sum_{r \in S_{h i}} c^{r} \cdot q_{k} \cdot x_{h i r}^{k}+\sum_{j \in \Gamma_{i}^{+}} \sum_{r \in S_{i j}} c^{s} \cdot q_{k} \cdot x_{i j s}^{k}\right) \\
& +\sum_{k \in K} \sum_{(i, j) \in A}\left(\sum_{s \in \Psi_{i j}} c_{3}^{\mathrm{rail}} \cdot q_{k} \cdot \frac{\delta_{i j s k}^{1}+\delta_{i j s k}^{2}+\delta_{i j s k}^{3}+\delta_{i j s k}^{4}}{4}+\sum_{s \in \Omega_{i j}} c_{3}^{\text {rail }} \cdot q_{k} \cdot \varphi_{i j s}^{k}\right)
\end{aligned}
$$

$$
\begin{array}{r}
\operatorname{minimize} \sum_{k \in K} \sum_{(i, j) \in A}\left(\sum_{s \in \Omega_{i j}} \sum_{p \in P_{i j}^{s}} \frac{e_{i j s p}^{1}+e_{i j s p}^{2}+e_{i j s p}^{3}+e_{i j s p}^{4}}{4}\right. \\
\left.\cdot d_{i j}^{s} \cdot q_{k} \cdot w_{i j s k}^{p}+\sum_{s \in \Psi_{i j}} e_{i j}^{s} \cdot q_{k} \cdot d_{i j}^{s} \cdot x_{i j s}^{k}\right)
\end{array}
$$

\section{Defuzzification of the fuzzy constraints}

There are four constraints (i.e., Eqs. (23), (24), (27), and (28)) in the FMOMINLP model that are fuzzy, and each one of them represents a fuzzy event. This study constructs their fuzzy chance constraint forms to realize their defuzzification. In the FCCP model, determining the fuzzy measure of a fuzzy event is the first step of establishing the chance constraints. events in the fuzzy constraints. As a result, the credibilitybased chance constraints of Eqs. (23), (24), (27), and (28) are modeled as follows.

$$
\begin{aligned}
& \operatorname{Cr}\left\{\tilde{y}_{i k}+\tilde{z}_{i j s k} \leq o_{i}^{k} \cdot x_{i j s}^{k}+L \cdot\left(1-x_{i j s}^{k}\right)-q_{k} \cdot t_{i}^{s}\right\} \\
& \quad \geq \lambda_{1} \forall k \in \forall(i, j) \in \forall s \in \Psi_{i j} \\
& \operatorname{Cr}\left\{\sum_{k \in K} q_{k} \cdot x_{i j s}^{k} \leq \tilde{g}_{i j s}\right\} \geq \lambda_{2} \forall(i, j) \in A \forall s \in \Psi_{i j} \\
& \operatorname{Cr}\left\{\tilde{y}_{\epsilon_{k} k} \geq \eta_{k}^{1}+\varpi_{k} \cdot\left(\eta_{k}^{2}-\eta_{k}^{1}\right)\right\} \geq \lambda_{3} \forall k \in K \\
& \operatorname{Cr}\left\{\tilde{y}_{\epsilon_{k} k} \leq \eta_{k}^{4}-\varpi_{k} \cdot\left(\eta_{k}^{4}-\eta_{k}^{3}\right)\right\} \geq \lambda_{4} \forall k \in K
\end{aligned}
$$


In above chance constraints, $\lambda_{1,2,3,4}$ are the confidence levels that indicate the minimum degree accepted by the decision-makers that the fuzzy event holds, and can be treated as the minimum feasibility degree of the routing optimization that is accepted by decision-makers. $\lambda_{1,2,3,4}$ fall into range $[0,1]$ and are set by decision-makers based on their preferences before solving the problem.

Furthermore, as for a trapezoidal fuzzy number $\tilde{\rho}=$ $\left(\rho_{1}, \rho_{2}, \rho_{3}, \rho_{4}\right)$ and a deterministic number $f$, the credibility measures of $\tilde{\rho} \geq f$ and $\tilde{\rho} \leq f$ are derived as follows [59].

$\operatorname{Cr}\{\tilde{\rho} \geq f\}=\left\{\begin{array}{ccc}1, & \text { if } & f \leq \rho_{1} \\ \frac{2 \rho_{2}-\rho_{1}-f}{2\left(\rho_{2}-\rho_{1}\right)}, & \text { if } & \rho_{1} \leq f \leq \rho_{2} \\ \frac{1}{2}, & \text { if } & \rho_{2} \leq f \leq \rho_{3} \\ \frac{\rho_{4}-f}{2\left(\rho_{4}-\rho_{3}\right)}, & \text { if } & \rho_{3} \leq f \leq \rho_{4} \\ 0 & \text { if } & f \geq \rho_{4}\end{array}\right.$
$\operatorname{Cr}\{\tilde{\rho} \leq f\}=\left\{\begin{array}{clc}0, & \text { if } & f \leq \rho_{1} \\ \frac{f-\rho_{1}}{2\left(\rho_{2}-\rho_{1}\right)}, & \text { if } & \rho_{1} \leq f \leq \rho_{2} \\ \frac{1}{2}, & \text { if } & \rho_{2} \leq f \leq \rho_{3} \\ \frac{f-2 \rho_{3}+\rho_{4}}{2\left(\rho_{4}-\rho_{3}\right)}, & \text { if } & \rho_{3} \leq f \leq \rho_{4} \\ 1, & \text { if } & f \geq \rho_{4}\end{array}\right.$

In practical decision-making, the confidence level is usually set within $[0.5,1.0]$ [60]. In this case, $\operatorname{Cr}\{\tilde{\rho} \geq f\} \geq \lambda$ and $\operatorname{Cr}\{\tilde{\rho} \leq f\} \geq \lambda$ can be rewritten as follows where $\lambda \in$ $[0.5,1.0]$.

$$
\begin{aligned}
\operatorname{Cr}\{\tilde{\rho} \geq f\} & \geq \lambda \Leftrightarrow \frac{2 \rho_{2}-\rho_{1}-f}{2\left(\rho_{2}-\rho_{1}\right)} \\
& \geq \lambda \Leftrightarrow(2 \lambda-1) \rho_{1}+2(1-\lambda) \rho_{2} \geq f \\
\operatorname{Cr}\{\tilde{\rho} \leq f\} & \geq \lambda \Leftrightarrow \frac{f-2 \rho_{3}+\rho_{4}}{2\left(\rho_{4}-\rho_{3}\right)} \\
& \geq \lambda \Leftrightarrow 2(1-\lambda) \rho_{3}+(2 \lambda-1) \rho_{4} \leq f
\end{aligned}
$$

Based on Eqs. (50) and (51), the equivalent crisp forms of the chance constraints are derived as follows.

$$
\begin{aligned}
& 2\left(1-\lambda_{1}\right)\left(y_{i k}^{3}+z_{i j s k}^{3}\right)+\left(2 \lambda_{1}-1\right)\left(y_{i k}^{4}+z_{i j s k}^{4}\right) \\
& \leq o_{i}^{k} \cdot x_{i j s}^{k}+L \cdot\left(1-x_{i j s}^{k}\right)-q_{k} \cdot t_{i}^{s} \\
& \forall k \in K \forall(i, j) \in A \forall s \in \Psi_{i j}
\end{aligned}
$$

$$
\begin{aligned}
& \left(2 \lambda_{2}-1\right) g_{i j s}^{1}+2\left(1-\lambda_{2}\right) g_{i j s}^{2} \\
& \geq \sum_{k \in K} q_{k} \cdot x_{i j s}^{k} \quad \forall(i, j) \in A \quad \forall s \in \Psi_{i j} \\
& \left(2 \lambda_{3}-1\right) y_{\epsilon_{k} k}^{1}+2\left(1-\lambda_{3}\right) y_{\epsilon_{k} k}^{2} \\
& \geq \eta_{k}^{1}+\varpi_{k} \cdot\left(\eta_{k}^{2}-\eta_{k}^{1}\right) \quad \forall k \in K
\end{aligned}
$$

$$
\begin{aligned}
& 2\left(1-\lambda_{4}\right) y_{\epsilon_{k} k}^{3}+\left(2 \lambda_{4}-1\right) y_{\epsilon_{k} k}^{4} \\
& \quad \leq \eta_{k}^{4}-\varpi_{k} \cdot\left(\eta_{k}^{4}-\eta_{k}^{3}\right) \quad \forall k \in K
\end{aligned}
$$

After the processing shown in "Defuzzification of the fuzzy objective functions" and "Defuzzification of the fuzzy constraints", we can get the FCCP based MOMINLP model. The objective functions are Eqs. (42) and (43), and the constraints include Eqs. (8)-(15), (17), (19), (21), (22), (25), (26), (29)-(36), and (52)-(55). After excluding the fuzziness, the MOMINLP model is solvable compared with the initial FMOMINLP form.

\section{Model linearization to obtain a MOMILP model}

By implementing the algorithms embedded, mathematical programming software, e.g., LINGO and CPLEX, can effectively solve the problems to obtain their optimum solutions. However, mathematical programming software is most suitable to solve linear programming models. The solutions may be local optimum and even unattainable within an acceptable computational time when using mathematical programming software to solve nonlinear programming models [61]. Consequently, when the optimization problems cannot be modeled by linear programming straightforwardly, their nonlinear programming models should be linearized before being solved using the mathematical programming software [62-64].

It is obvious that the FCCP model designed in this study is nonlinear, since it is associated with nonlinearity caused by the integral floor function in Eqs. (13) and (14), multiplication of variables in Eqs. (15), (17), and (21), and maximum function in Eqs. (17), (19), and (21). To make the FCCP model easier to be solved using mathematical programming software, this study linearizes the MOMINLP model using the linearization method proposed by the authors' previous articles [9, 22, 31].

By adding an auxiliary non-negative integer variable as Eq. (56) whose lower bound and upper bound are as Eqs. (57) and (58), respectively, Eqs. (13) and (14) can be linearized as Eqs. (59) and (60) [22]. 
$\psi_{i j s}^{k} \geq 0$ and integer $\forall k \in K \quad \forall(i, j) \in A \forall s \in \Omega_{i j}$

$\psi_{i j s}^{k} \leq \frac{u_{i}^{k}+q_{k} \bullet t_{i}^{s}}{24} \forall k \in K \quad \forall(i, j) \in A \forall s \in \Omega_{i j}$

$\psi_{i j s}^{k}>\frac{u_{i}^{k}+q_{k} \bullet \iota_{i}^{s}}{24}-1 \forall k \in K \forall(i, j) \in A \forall s \in \Omega_{i j}$

$u_{i}^{k}+q_{k} \cdot t_{i}^{s}-24 \cdot \psi_{i j s}^{k} \geq a_{i j s}^{p}+L \cdot\left(w_{i j s k}^{p}-1\right)$

$$
\forall k \in K \quad \forall(i, j) \in A
$$$$
\forall s \in \Omega_{i j} \quad \forall p \in P_{i j}^{s}
$$

$$
\begin{array}{r}
u_{i}^{k}+q_{k} \cdot t_{i}^{s}-24 \cdot \psi_{i}^{k} \leq b_{i j s}^{p}+L \cdot\left(1-w_{i j s k}^{p}\right) \\
\forall k \in K \quad \forall(i, j) \in A \\
\forall s \in \Omega_{i j} \quad \forall p \in P_{i j}^{s}
\end{array}
$$

According to Sun and Lang [31], Eq. (15) can be linearized by Eqs. (61) and (62).

$u_{i}^{k}+q_{k} \cdot t_{i}^{s}+\sum_{p \in P_{i j}^{s}} t_{i j s p}^{m} \cdot w_{i j s k}^{p}+q_{k} \cdot t_{j}^{s}-y_{j k}^{m} \geq L \cdot\left(x_{i j s}^{k}-1\right)$
$\forall k \in K \forall(i, j) \in A \quad \forall s \in \Omega_{i j} \forall m \in\{1,2,3,4\}$

$u_{i}^{k}+q_{k} \cdot t_{i}^{s}+\sum_{p \in P_{i j}^{s}} t_{i j s p}^{m} \cdot w_{i j s k}^{p}+q_{k} \cdot t_{j}^{s}-y_{j k}^{m} \leq L \cdot\left(1-x_{i j s}^{k}\right)$

$\forall k \in K \forall(i, j) \in A \quad \forall s \in \Omega_{i j} \forall m \in\{1,2,3,4\}$

Equations (17), (19) and, (21) can be linearized by following equations, respectively, which have been proved by Sun [9].

$$
\begin{aligned}
z_{i j s k}^{m} & \geq l_{i}^{s}-y_{i k}^{(5-m)}+L \cdot\left(x_{i j s}^{k}-1\right) \quad \forall k \\
& \in K \quad \forall(i, j) \in A \quad \forall s \in \Psi_{i j} \quad \forall m \in\{1,2,3,4\}
\end{aligned}
$$

$\delta_{i j s k}^{m} \geq z_{i j s k}^{m}-\theta \quad \forall k \in K \quad \forall(i, j)$

$\in A \quad \forall s \in \Psi_{i j} \quad \forall m \in\{1,2,3,4\}$

$\varphi_{i j s}^{k} \geq u_{i}^{k}-\sum_{h \in \Gamma_{i}^{-}} \sum_{r \in \Psi_{h i}}\left(l_{i}^{r}+q_{k} \cdot t_{i}^{r}\right) \cdot x_{h i r}^{k}-\theta+L \cdot\left(x_{i j s}^{k}-1\right)$

$\forall k \in K \quad \forall i \in N \backslash\left\{\tau_{k}\right\} \forall(i, j) \in A \quad \forall s \in \Omega_{i j}$

After model defuzzification and linearization, an auxiliary crisp MOMILP model is generated. It is equivalent to the proposed FMOMINLP model in "Model formulation". Its objective functions are as Eqs. (42) and (43), and constraints include Eqs. (8)-(12), (22), (25), (26), (29)-(36), and (52)-(65). Moreover, it is a parametric model. Before solving this model, parameters including $\xi_{k}, \varpi_{k}$, and $\lambda_{1,2,3,4}$ reflect decision-makers' subjective preferences and should be determined by them in advance. The combination of the
Table 2 Payoff table for the multi-objective road-rail intermodal routing problem

\begin{tabular}{lll}
\hline Objectives of MILP model & $F_{1}$ values & $F_{2}$ values \\
\hline Minimize $F_{1}$ & $F_{1}\left(\Gamma_{1}^{\mathrm{PIS}}\right)=F_{1}^{\mathrm{PIS}}$ & $F_{2}\left(\Gamma_{1}^{\mathrm{PIS}}\right)=F_{2}^{\mathrm{NIS}}$ \\
Minimize $F_{2}$ & $F_{1}\left(\Gamma_{2}^{\mathrm{PIS}}\right)=F_{1}^{\mathrm{NIS}}$ & $F_{2}\left(\Gamma_{2}^{\mathrm{PIS}}\right)=F_{2}^{\mathrm{PIS}}$ \\
\hline
\end{tabular}

above parameters shows a specific decision-making situation.

\section{Interactive fuzzy programming approach}

After processing the proposed FMOMINLP model, we can finally obtain its equivalent MOMILP form that is easier to be solved. Based on the multi-objective solution approach, we can employ mathematical programming software to implement exact solution algorithms embedded in it to solve the MOMILP model to find its global optimum solutions.

Currently, there are many solution approaches to solve the multi-objective linear programming models in the literature, in which interactive fuzzy programming approaches are widely applied in recent years. Interactive fuzzy programming approaches can measure and adjust the satisfaction degree of each objective function straightforwardly [65]. They integrate the advantages of the priori and postpriori approaches and avoid their disadvantages by considering the decision-makers' preferences on the satisfaction degree of each objective to provide Pareto solutions and using interactive nature to improve the computational efficiency [53].

To apply the interactive fuzzy programming approach, we should first determine the positive ideal solution (PIS) and negative ideal solution (NIS) for each objective function after parameters including $\xi_{k}, \varpi_{k}$, and $\lambda_{1,2,3,4}$ are specified by decision-makers. By solve the MILP model for each objective function separately, we can obtain the PIS and NIS illustrated by the payoff table as Table 2 .

In Table 2, $F_{1}$ and $F_{2}$ represent the economic objective function and environmental objective function, respectively. $\Gamma_{1}^{\mathrm{PIS}}$ and $\Gamma_{2}^{\mathrm{PIS}}$ are the PIS for the economic objective function and environmental objective function, respectively. They result in $F_{1}^{\mathrm{PIS}}$ and $F_{2}^{\mathrm{PIS}}$ that are the lower bounds of the economic objective values and environmental objective values, respectively. Furthermore, $\Gamma_{1}^{\mathrm{PIS}}$ is the NIS for the minimization of the environmental objective and leads to $F_{2}^{\mathrm{NIS}}$ that is the upper bound of the environmental objective values. Similarly, as the NIS for the minimization of the economic objective, $\Gamma_{2}^{\mathrm{PIS}}$ makes the economic objective reach up to its upper bound denoted by $F_{1}^{\mathrm{NIS}}$.

Then based on the PIS and NIS, we can establish a linear membership function as Eq. (66) for each objective to measure its satisfaction degree shown in Fig. 6. In Eq. (66), $\mu$ 
Fig. 6 Linear membership function for $F_{n}$
Satisfaction degree of objective n

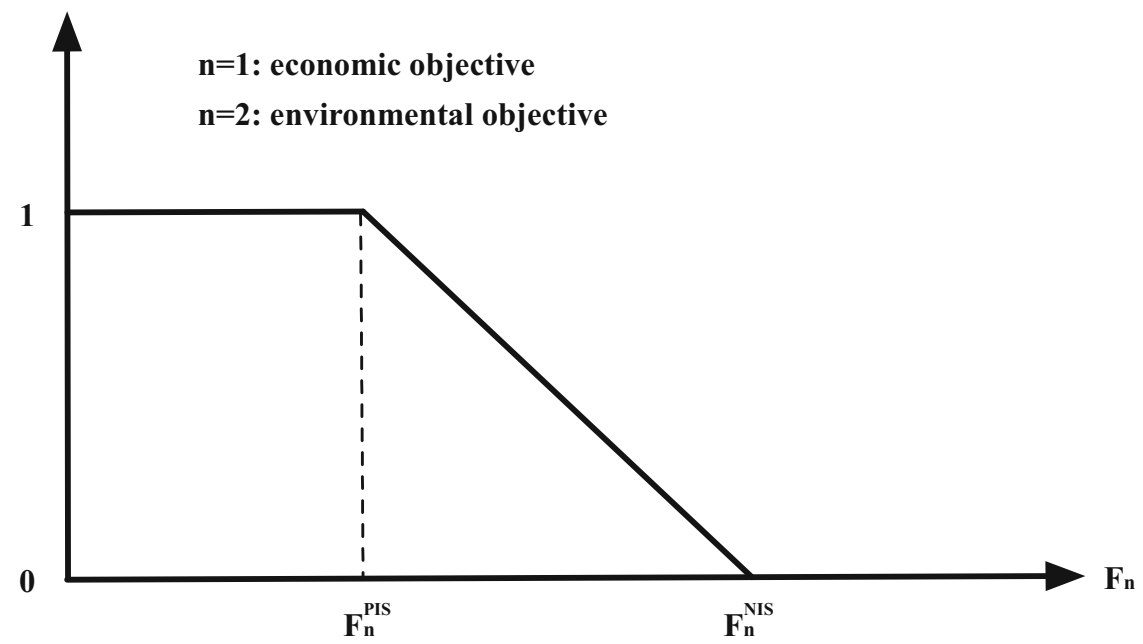

$\left(F_{n}\right)$ is defined as the satisfaction degree of objective $n$, and $\mu\left(F_{n}\right) \in[0,1]$.

$\mu\left(F_{n}\right)=\left\{\begin{array}{cc}1, & \text { if } F_{n}<F_{n}^{\mathrm{PIS}} \\ \frac{F_{n}^{\mathrm{NIS}}-F_{n}}{F_{n}^{\mathrm{NIS}}-F_{n}^{\mathrm{PIS}},} & \text { if } F_{n}^{\mathrm{PIS}} \leq F_{n} \leq F_{n}^{\mathrm{NIS}} \quad \forall n=1,2 \\ 0, & \text { if } F_{n}>F_{n}^{\mathrm{NIS}}\end{array}\right.$

Based on the interactive fuzzy programming approach, the two objectives of the MOMILP model are converted into the maximization of their satisfaction degrees. The model cannot simultaneously optimize the two objectives that maximize the satisfaction degrees. A multi-objective solution approach is thereby required to make compromises between the two conflicting objectives. In this study, we use the Bounded Objective Function (BOF) method to convert the MOMILP model into a single-objective one.

In the BOF method, one objective, usually the most important one preferred by decision-makers, remains as the objective function, while the others are treated as constraints with lower or upper bounds assigned to them [38, 66]. Minimizing the total costs is the most concerning issue in transportation planning [11, 67]. Therefore, maximizing its satisfaction degree remains the objective. However, the satisfaction degree of the environmental objective function is concerted into a constraint with a lower bund LB, since it is a maximum function. As a result, the MOMILP model can be reformulated as follows.

$\operatorname{maximize} \mu\left(F_{1}\right)$

s.t. $\left\{\begin{array}{l}\mu\left(F_{2}\right) \geq L B \\ \text { Equations (8) - (12), (22), (25), (26), (29) - (36), and (52) - (66) }\end{array}\right.$
In the interactive fuzzy programming approach with the BOF method, by varying the values of LB, Pareto solutions to the problem can be obtained. The satisfaction degree of the environmental objective function is used in the model. Therefore, LB falls into range $[0,1]$, which makes it easy to segment the range of LB into equal parts and use the grid points as the values of LB to obtain balanced solutions with no significant difference between satisfaction degrees of objectives and unbalanced ones whose satisfaction degrees of objectives significantly differ from each other [65].

Notably, when any one of $\xi_{k}, \varpi_{k}$, and $\lambda_{1,2,3,4}$ is changed by the decision-makers, the PIS and NIS for each objective should be calculated again to obtain new Pareto solutions.

\section{Empirical case study}

This section presents an empirical case study that is oriented on the Chinese scenario to verify the validity of the proposed approach. Case analysis is also carried out to draw some insights that can help decision-makers to better organize the transportation.

\section{Case design}

\section{Case description}

The case is oriented on the scenario where containers should be transported from Lanzhou (LZ) that is an inland city that serves as a major freight source at northwestern China to Lianyungang (LYG), a seaport that is located at the eastern China and plays an important role in China's imports and exports. Considering LZ and LYG as the respective origin and destination of the transportation, we establish a road-rail intermodal transportation network shown in Fig. 7. In Fig. 7, 


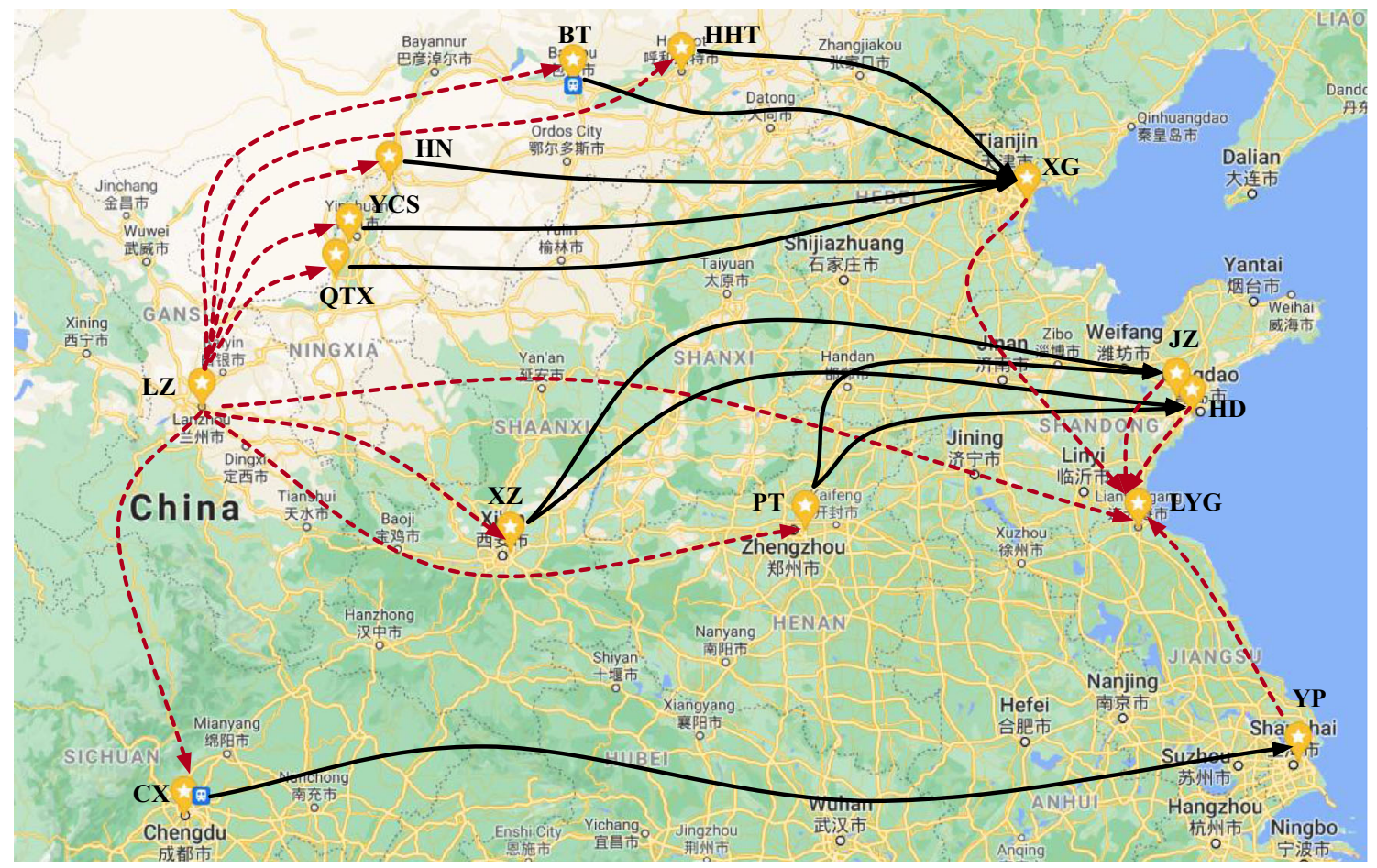

Fig. 7 Road-rail intermodal transportation network in the empirical case

the black lines represent rail services, and the red dot lines indicate road services.

In the transportation network illustrated by Fig. 7, the abbreviations of the rail terminals are shown in Table 3 .

The rail services and road services in the transportation network are given in Tables A1 and A2 in the Online Appendix. It should be noted that for the convenience of modeling, the same container block train in its different operation periods is modeled as different rail services with different service indexes [68]. In the Chinese scenario, the cost parameters are regulated by government departments and the values are accessible to the public at their official websites. Moreover, the time parameters of the operations of different transportation services are set by referring to the solid literature source. The values of all these parameters are summarized in Table 4, in which their sources are also indicated. Based on the transportation service information provided by Tables $\mathrm{A} 1$ and $\mathrm{A} 2$ and the parameter setting shown in Table 4, the proposed interactive fuzzy programming approach can be used to plan the road-rail intermodal routes for any transportation orders given by the empirical case.

In the empirical case study, we consider a planning horizon of 7 days. For the convenience of modeling and computation, the planning horizon starting from 0:00 on day 1 to 24:00 on day 7 is converted into a range $[0,168]$. All the values of time parameters are converted to corresponding real numbers that fall into this range. For example, if the scheduled operation start time of a train is $5: 30$ on day 2 , the input data should be 29.5 (i.e., $5+0.5+24$ ). Finally, we consider transportation orders listed in Table 5 as the object of the routing.

\section{Computing environment}

In this study, we utilize the well-known LINGO optimizer developed by LINDO Systems Inc. [72] to solve the problem, in which the branch-and-bound algorithm is implemented by the optimizer to solve the MOMILP model with the help of the interactive fuzzy solution approach. This algorithm is an exact solution version, and can thereby find the global optimum solutions. In this study, all the computations are performed on a ThinkPad Laptop with Intel Core i5-5200U $2.20 \mathrm{GHz}$ CPU 8 GB RAM. To further demonstrate the efficiency of the algorithm, the scale of the empirical case is indicated in Table 6.

\section{Optimization results and analysis}

\section{Pareto solutions to the empirical case}

The proposed model is parametric. Therefore, we first give a specific decision-making situation that: 
Table 3 Rail terminals in the empirical case

\begin{tabular}{lll}
\hline Abbreviations & Rail terminals & Locations \\
\hline BT & Baotou Railway Station & Baotou City, Inner Mongolia \\
HHT & Hohhot Railway Station & Hohhot City, Inner Mongolia \\
HN & Huinong Railway Station & Shizuishan City, Ningxia \\
YCS & Yinchuan South Railway Station & Yinchuan City, Ningxia \\
QTX & Qingtongxia Railway Station & Wuzhong City, Ningxia \\
XZ & Xinzhu Railway Station & Xi'an City, Shaanxi \\
CX & Chengxiang Railway Station & Chengdu City, Sichuan \\
PT & Putian Railway Station & Zhengzhou City, Henan \\
XG & Xingang Railway Station & Tianjin City \\
JZ & Jiaozhou Railway Station & Qingdao City, Shandong \\
HD & Huangdao Railway Station & Qingdao City, Shandong \\
YP & Yangpu Railway Station & Shanghai City \\
\hline
\end{tabular}

Table 4 Parameter setting in the empirical case

\begin{tabular}{llll}
\hline Parameters & Values & Units & Sources \\
\hline$c_{1}^{\text {rail }}$ & 440 & CNY per TEU & {$[69]$} \\
$c_{2}^{\text {rail }}$ & 3.185 & CNY per TEU per km & {$[69]$} \\
$c_{3}^{\text {rail }}$ & 3.125 & CNY per TEU per hour & {$[69]$} \\
$c^{\text {road }}$ & 6.0 & CNY per TEU per km & {$[70]$} \\
$c^{s}$ & $195(s=$ rail $) ; 25(s=$ road $)$ & CNY per TEU & {$[69,70]$} \\
$t_{i}^{s}$ & $0.2(s=$ rail $) ; 0.05(s=$ road $)$ & h per TEU & {$[71]$} \\
$\theta$ & 6.0 & $\mathrm{~h}$ & Set by this study \\
\hline
\end{tabular}

Table 5 Transportation orders in the empirical case

\begin{tabular}{llllll}
\hline No. & Origins & Destinations & Volumes in TEU & Pickup time windows & Delivery time windows \\
\hline 1 & LZ & LYGP & 21 & {$[5,9,12,14]$} & {$[90,95,103,111]$} \\
2 & LZ & LYGP & 19 & {$[20,24,28,33]$} & {$[135,142,152,161]$} \\
3 & LZ & LYGP & 14 & {$[10,14,18,24]$} & {$[126,133,142,149]$} \\
4 & LZ & LYGP & 16 & {$[16,20,25,29]$} & {$[80,88,98,106]$} \\
5 & LZ & LYGP & 32 & {$[22,28,34,38]$} & {$[134,140,148,154]$} \\
6 & LZ & LYGP & 16 & {$[7,13,18,22]$} & {$[102,110,119,125]$} \\
7 & LZ & LYGP & 22 & {$[26,30,36,42]$} & {$[125,133,142,148]$} \\
8 & LZ & LYGP & 32 & {$[30,37,42,46]$} & {$[140,145,155,163]$} \\
9 & LZ & LYGP & 30 & {$[12,15,19,23]$} & {$[95,102,112,119]$} \\
10 & LZ & LYGP & 25 & {$[19,23,29,35]$} & {$[126,135,144,151]$} \\
\hline
\end{tabular}

Table 6 Transportation orders in the empirical case

\begin{tabular}{lll}
\hline Number of variables & $\begin{array}{l}\text { Number of integer } \\
\text { variables }\end{array}$ & $\begin{array}{l}\text { Number of } \\
\text { constraints }\end{array}$ \\
\hline 3559 & 1120 & 7672 \\
\hline
\end{tabular}

(1) Minimum pickup service levels and delivery service levels for all transportation orders accepted by shippers and receivers are 0.8 , which reflects the shippers' and receivers' demands for high service levels.
(2) Decision-makers would not like to take a risk that the planned routes become infeasible due to capacity insufficiency and transshipment failure, which means that the minimum feasibility degree of the planned routes accepted by them is 1.0 .

Under above consideration, we set $\xi_{k}=\varpi_{k}=0.8$ and $\lambda_{1,2}=1.0$. Notably, we set $\lambda_{3,4}=1.0$ under any situations in the entire case study, which means that the minimum delivery service levels must be satisfied in practical transportation. This set is based on the consideration that if receivers accept the violation of a certain service level, it is more effective 
Table 7 Payoff table of the multi-objective road-rail intermodal routing problem

\begin{tabular}{lll}
\hline & $\begin{array}{l}\text { Economic objective } \\
\text { values in CNY }\end{array}$ & $\begin{array}{l}\text { Environmental } \\
\text { objective values in } \\
\mathrm{kg}\end{array}$ \\
\hline $\begin{array}{l}\text { Minimize of the } \\
\text { total costs } \\
\begin{array}{l}\text { Minimize of the } \\
\text { emissions }\end{array}\end{array}$ & $2,511,642$ & $388,544.3$ \\
\hline
\end{tabular}

for them to reselect a lower level than evaluate the values of $\lambda_{3,4}$ that are smaller than 1.0. First of all, we calculate the payoff table (Table 7) of the specific problem under the above situation. Table 7 shows that the two objectives of the problem cannot be optimized simultaneously. Therefore, Pareto solutions to the problem exist in the empirical case.

Based on the payoff table, we use interactive fuzzy solution approach with the BOF method to generate the Pareto solutions. We vary LB in Eq. (68) from 0 to 1.0 with a step of 0.1 , and obtain solutions under each value of LB. The results are presented in Table 8 .

The results in Table 8 confirm that the economic objective and the environmental objective are in conflict with each other. Improving one of the objectives will worsen the other one. With the help of the Pareto solutions, decision-makers can determine the most suitable one under a specific decisionmaking situation to plan road-rail intermodal route scheme.

For example, if decision-makers accept that the satisfaction degree of the environmental objective is not smaller than 0.5 , Pareto solution $(2514130,385358)$ is the best, since it meets decision-makers preference and yields the minimum economic objective value (i.e., the maximum satisfaction degree of the economic objective). A balanced solution obtained when LB is set to 0.7 or 0.8 can also be provided to decision-makers if they prefer balanced trade-offs between the two objectives.

\section{Result analysis}

We then calculate the carbon dioxide emitted by road and rail services in the solutions listed in Table 8 . The results are shown in Figs. 8 and 9. Compared with results shown in these tables, we can draw the following conclusions.

(1) Road services account for approximately $77 \%$ of the total emissions in each solution. Therefore, the road is the major contributor to the carbon dioxide emissions in the road-rail intermodal transportation.

(2) When total carbon dioxide emissions are reduced from the maximum value (i.e., $388,544.3 \mathrm{~kg}$ ) to its minimum value $t$ (i.e., $383,117.9 \mathrm{~kg}$ ) by routing, the road services contribute to a reduction of $4996.4 \mathrm{~kg}$ and account for approximately $92 \%$ of the total reduction, while the rail services only relate to a reduction of $430.0 \mathrm{~kg}$. Therefore, road services are also the key source of lowering carbon dioxide emissions.

(3) When LB changes from 0.4 to 0.5 , the reduction of carbon dioxide emissions is most significant. Emission variations of rail services and road services show the transfer of carbon dioxide emissions from road to rail. It indicates that decision-makers can select rail services with higher emissions when these rail services can cooperate with road services yielding lower emissions in certain periods of the planning horizon to formulate the routes.

To analyze the motivations that lead to the reduction of carbon dioxide emissions in transportation, we further check the variations of the travel costs and in-transit inventory costs in the solutions in Table 8, and analyze the results by Figs. 10 and 11. It should be noted that the loading and unloading operation costs are not sensitive to LB and remain 111,230 for all $\mathrm{LB} \in\{0.2,0.5,0.8\}$. Thus, the loading and unloading operation does not influence the results.

Figures 10 and 11 show that the travel costs and in-transit inventory costs change with the increase of LB to achieve lower carbon dioxide emissions. In the empirical case, the parameters of different transportation services related to travel costs differ from each other. Therefore, the variation of travel costs indicates the change of transportation services in the planned routes. Meanwhile, the in-transit inventory costs are the multiplication of a fixed inventory cost rate with the charged in-transit inventory period. The variation of the in-transit inventory costs represents the change of the charged in-transit inventory period, and further reveals that the planned truck departure times of road services are modified.

Figures 10 and 11 explain two approaches to reduce carbon dioxide emissions in transportation. However, both of they may lead to the increase of the total costs of the transportation in whole or part.

(1) Replacing transportation services with those whose yield lower carbon dioxide emissions, and changing the road-rail intermodal routes. However, as illustrated by Fig. 10, this approach is restricted, since the transportation services available in the transportation network are limited.

(2) Planning truck departure times for road services to avoid the transportation in the periods when the road services have higher carbon dioxide emission factors, for example, the period when there is traffic congestion, which however, will result in the waiting of containers at the nodes. 
Table 8 Solutions of the multi-objective road-rail intermodal routing problem

Fig. 8 Carbon dioxide emitted by rail services in different solutions

\begin{tabular}{|c|c|c|c|c|c|}
\hline \multirow[t]{2}{*}{ LB } & \multicolumn{2}{|c|}{$\begin{array}{l}\text { Satisfaction } \\
\text { degrees }\end{array}$} & \multicolumn{2}{|l|}{ Objective values } & \multirow[t]{2}{*}{$\begin{array}{l}\text { CPU time } \\
\text { (s) }\end{array}$} \\
\hline & $\mu\left(F_{1}\right)$ & $\mu\left(F_{2}\right)$ & $\begin{array}{l}F_{1} \\
\text { (Total costs in } \mathrm{CNY} \text { ) }\end{array}$ & $\begin{array}{l}F_{2} \\
\text { (Total emissions in } \mathrm{kg} \text { ) }\end{array}$ & \\
\hline 0 & 1.0 & 0 & $2,511,642$ & $388,544.3$ & 40 \\
\hline 0.1 & 0.978 & 0.111 & $2,511,982$ & $387,939.5$ & 38 \\
\hline 0.2 & 0.968 & 0.231 & $2,512,137$ & $387,293.4$ & 26 \\
\hline 0.3 & 0.966 & 0.305 & $2,512,162$ & $386,889.2$ & 34 \\
\hline 0.4 & 0.913 & 0.406 & $2,512,982$ & $386,342.6$ & 40 \\
\hline 0.5 & 0.839 & 0.587 & $2,514,130$ & $385,358.0$ & 38 \\
\hline 0.6 & 0.818 & 0.645 & $2,514,447$ & $385,044.6$ & 42 \\
\hline 0.7 & 0.807 & 0.818 & $2,514,625$ & $384,107.1$ & 32 \\
\hline 0.8 & 0.807 & 0.818 & $2,514,625$ & $384,107.1$ & 31 \\
\hline 0.9 & 0.766 & 0.909 & $2,515,262$ & $383,613.8$ & 29 \\
\hline 1.0 & 0 & 1.0 & $2,527,123$ & $383,117.9$ & 32 \\
\hline
\end{tabular}

\section{Cabon dioxide in $\mathrm{kg}$ emitted by rail services}

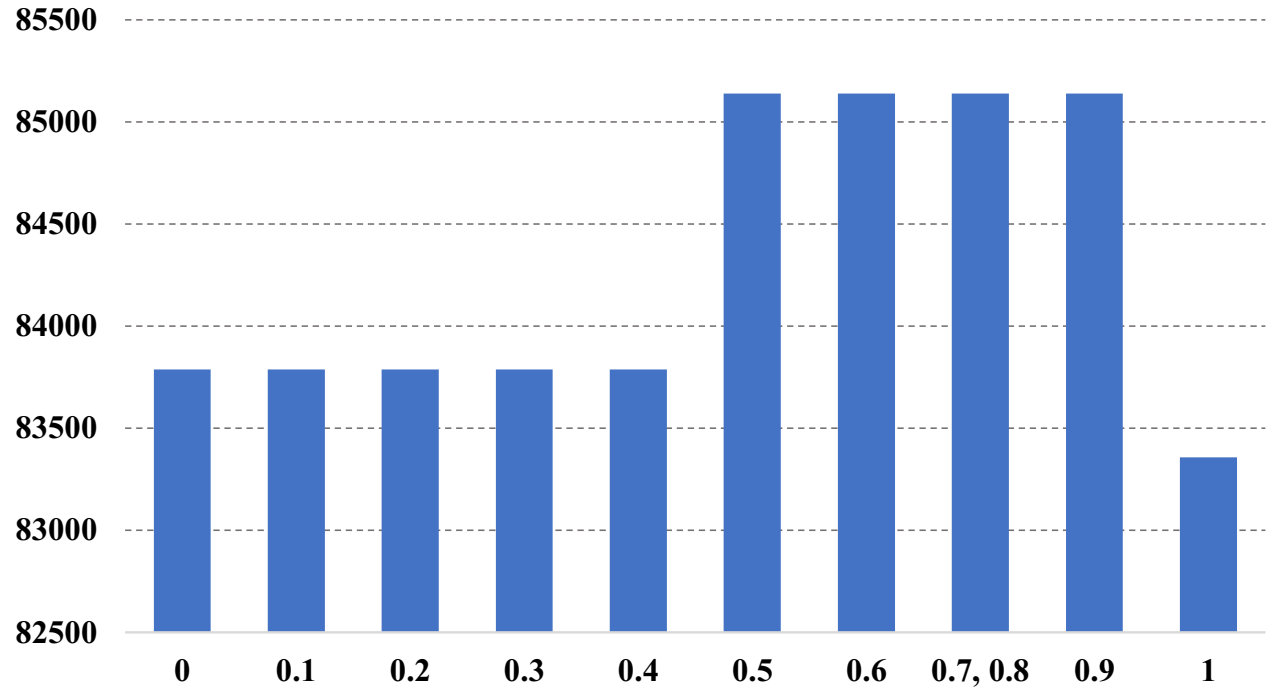

LB of the satisfaction degree of the environmental objective
Thus, compared with existing literature, this study provides one more option to help decision-makers to improve the environmental objective by formulating the truck departure time planning for road services based on the variation of their carbon dioxide emission factors in different periods of the planning horizon.

\section{Sensitivity analysis on the optimization results with respect to the confidence levels}

In this section, under the decision-making situation that $\xi_{k}=\varpi_{k}=0.8$ and $\lambda_{3,4}=1.0$, different values of $\lambda_{1,2}$ (i.e., $\lambda_{1,2}=0.5,0.6,0.7,0.8,0.9$, and 1.0) are used to test the optimization model to analyze the sensitivity of the routing optimization with respect to the confidence levels. The val- ues of LB reflect the decision-makers' acceptable minimum satisfaction degrees on the environmental objective. We set LB as $0.2,0.5$, and 0.8 that refer to the low, medium, and high degrees, respectively, and calculate the optimization results for each value of $\lambda_{1,2}$ under different LB. The results are shown in Figs. 12 and 13.

Figures 12 and 13 illustrate that the two objectives are sensitive to $\lambda_{1,2}$ when $\lambda_{1,2}$ varies from 0.7 to 1.0 , regardless of the settings of LB. The values of both objectives increase when improving the confidence levels, which means that if the decision-makers decide to deal with the uncertainty with a higher feasibility degree, the total costs and carbon dioxide emissions of the planned routes are augmented. The potential reasons behind Figs. 12 and 13 are as follows. 
Fig. 9 Carbon dioxide emitted by road services in different solutions

Fig. 10 Travel costs in different solutions

\section{Cabon dioxide in $\mathrm{kg}$ emitted by road services}

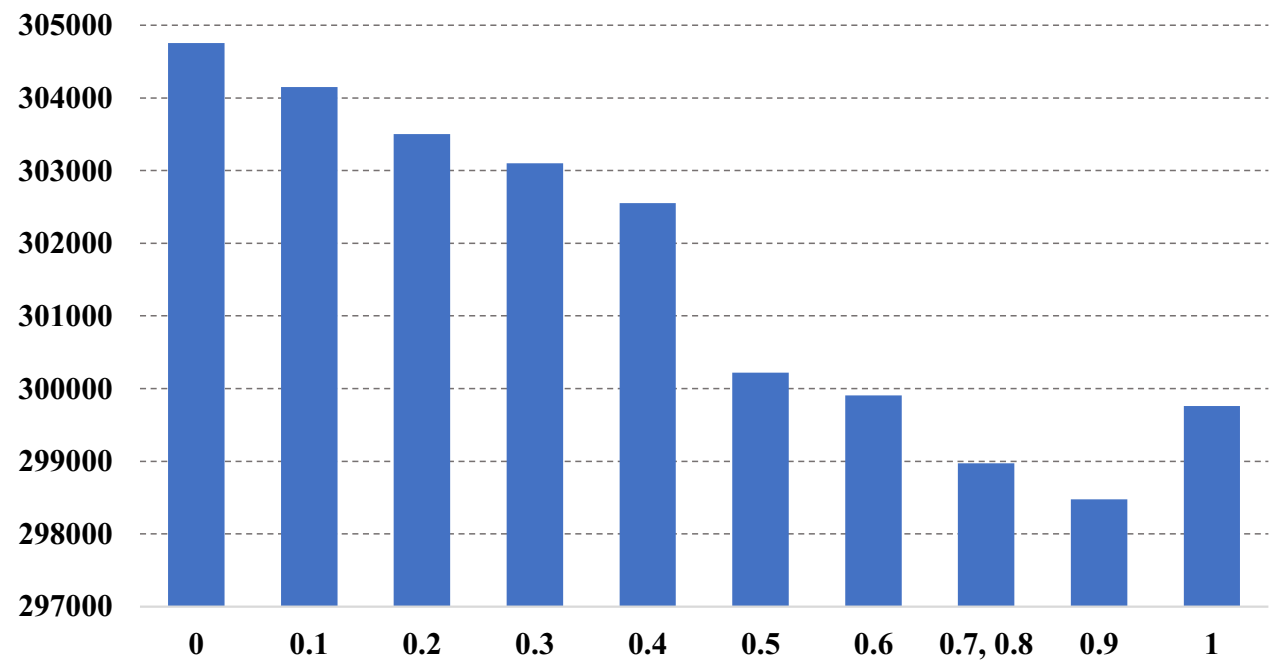

LB of the satisfaction degree of the environmental objective

\section{Travel costs in $\mathrm{CNY}$}

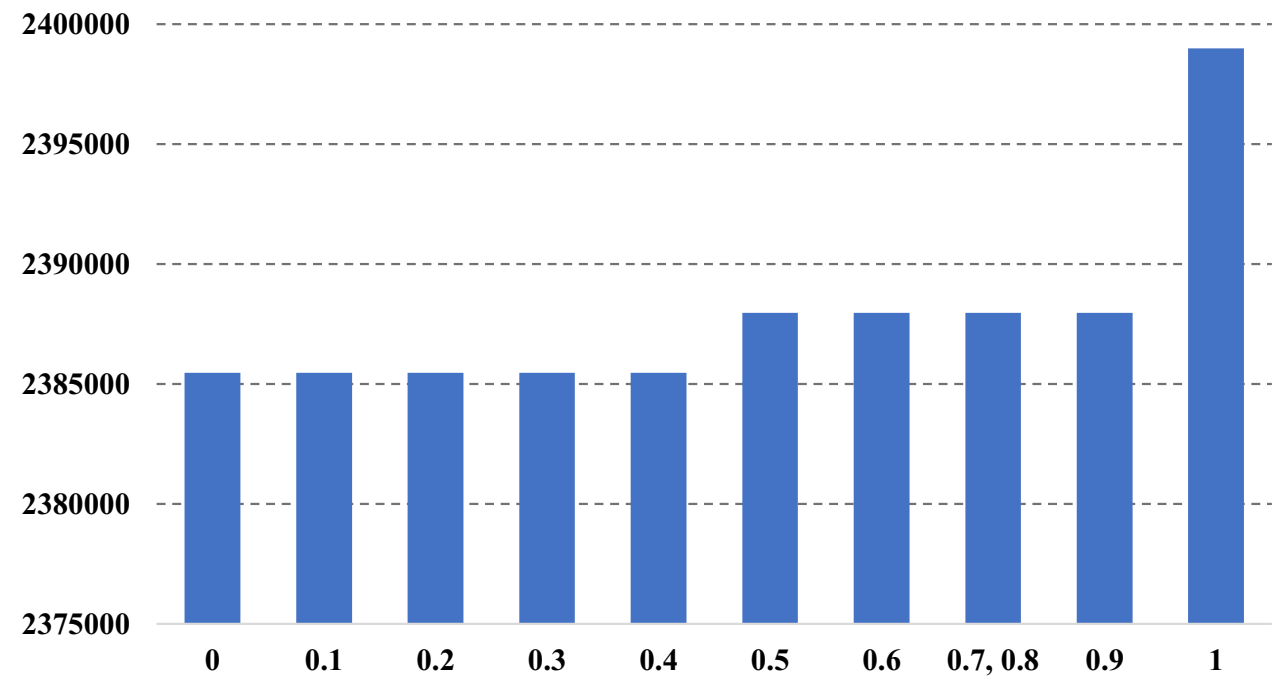

LB of the satisfaction degree of the environmental objective
(1) To achieve a higher feasibility degree on satisfying the capacity constraint, rail services with insufficient capacities will not be considered to be used for the routing. This leads to a significant limitation on the utilization of rail services that are cost-efficient and environmentally friendly.

(2) To achieve a higher feasibility degree on satisfying the scheduled operation time window constraint, road services should arrive at the rail terminals earlier, which restricts the planned truck departure times and further makes some periods in which road services emit fewer carbon dioxides unsuitable.
In practical decision-making, a solution under a higher confidence level can be selected when decision-makers have cost and emission budgets [51]. For example, when the cost budget is $2510000 \mathrm{CNY}$ and the emission budget is $3,80,000 \mathrm{~kg}$, the solutions under $\lambda_{1,2}=0.9$ are most suitable for the decision-making situations where $\xi_{k}=\varpi_{k}=$ $0.8, \lambda_{3,4}=1.0$, and LB $\in\{0.2,0.5,0.8\}$. Moreover, the decision-makers can also select a suitable solution based on the sensitivity analysis if minimum confidence levels accepted by them can be determined. 
Fig. 11 In-transit inventory costs in different solutions

Fig. 12 Sensitivity of the economic objective with respect to the confidence levels

\section{In-transit inventory costs in $\mathrm{CNY}$}

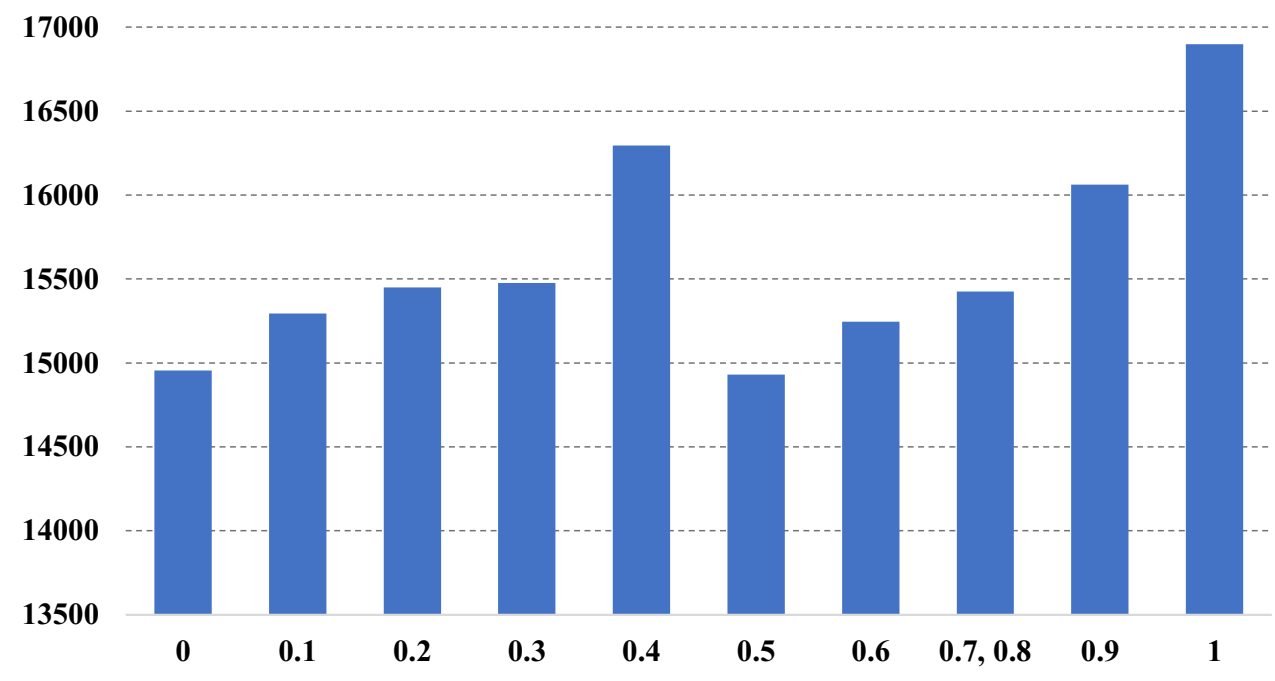

LB of the satisfaction degree of the environmental objective

Economic objective values in CNY

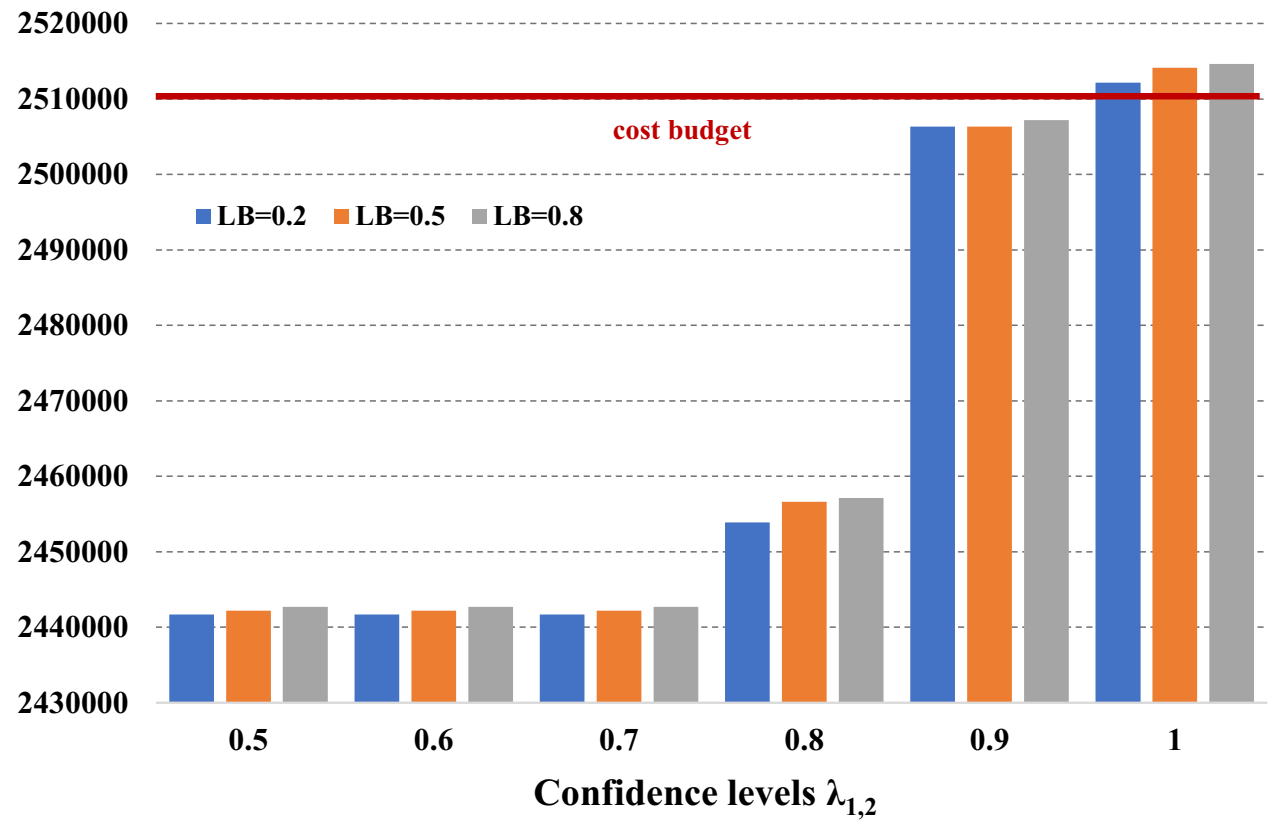

\section{Sensitivity analysis on the optimization results with respect to the service levels}

In this section, under the decision-making situation that $\lambda_{1,2}=0.9, \lambda_{3,4}=1.0$, and LB $\in\{0.2,0.5,0.8\}$, different values of $\xi_{k}$ and $\varpi_{k}$ (i.e., $\xi_{k}=\varpi_{k}=0.5,0.6,0.7,0.8$, 0.9 , and 1.0) are used to test the optimization model to analyze the sensitivity of the routing optimization with respect to the service levels. We obtain the optimization results for each value of $\xi_{k}$ and $\varpi_{k}$ under different LB. The results are shown in Figs. 14 and 15. The following conclusions can be summarized from the two figures.

(1) The two objectives are sensitive to the service levels of pickups and deliveries. Therefore, determining suitable service levels is necessary when planning the road-rail intermodal routes.

(2) The total costs of the planned routes increase with the improvement of the service levels regardless of LB, which gives a clear evidence that customers need to pay more to get better services. 
Fig. 13 Sensitivity of the environmental objective with respect to the confidence levels
Fig. 14 Sensitivity of the economic objective with respect to the service levels

\section{Environmental objective values in kg}

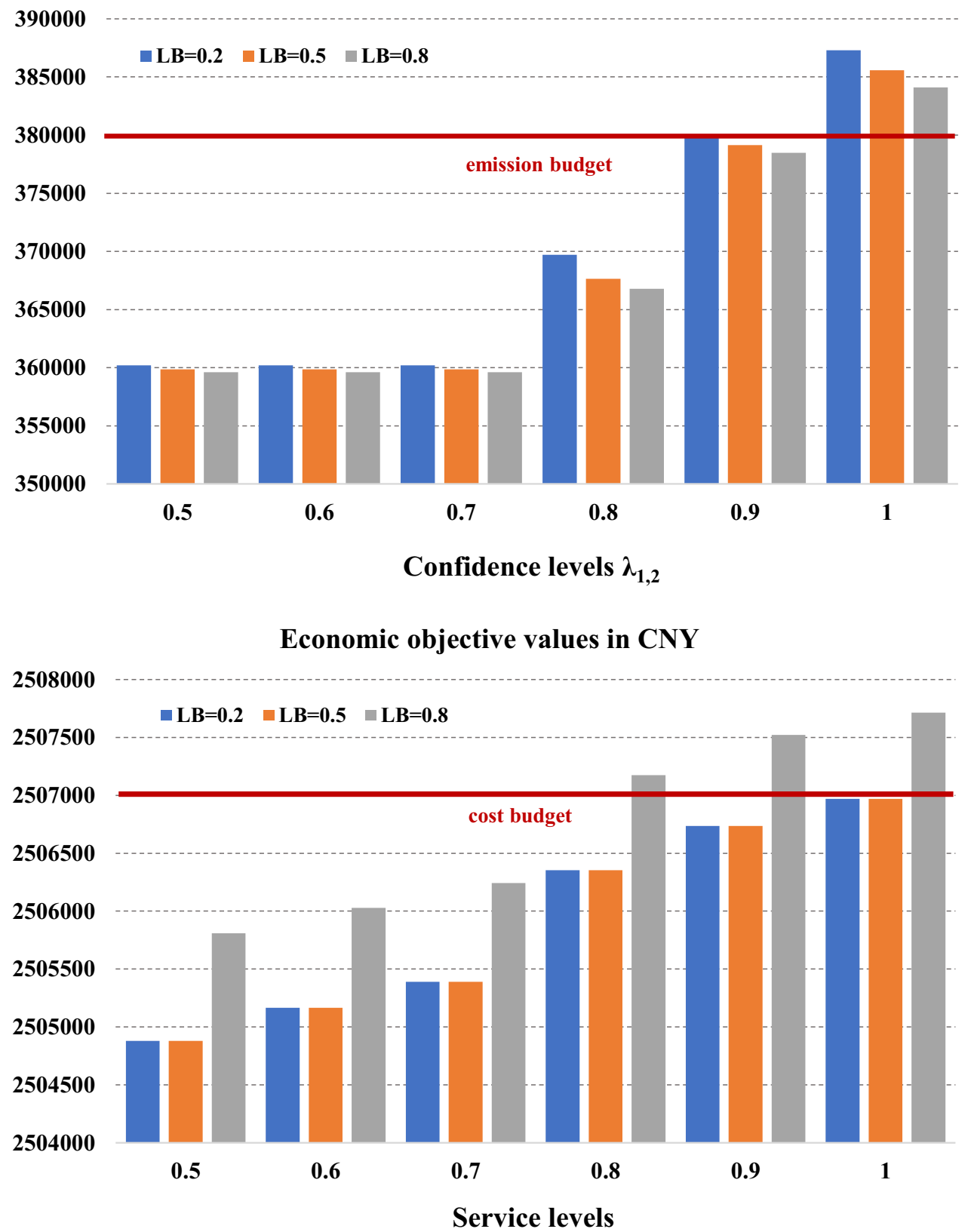

(3) The effect of improving service levels on the environmental objective is not as stable as its effect on the economic objective. With an occasional increase, the environmental objective values decrease in general when the service levels are improved, and smaller LB leads to a more significant decrease.

Similar to the analysis on the confidence levels, when the decision-makers determine the budgets for the total costs and carbon dioxide emissions, the sensitivity can help them to identify the most suitable solution that can meet the budget constraints and yields the highest service levels. For example, if the cost budget is $2507000 \mathrm{CNY}$ and the emission budget is $3,81,000 \mathrm{~kg}$, the most suitable solution under $\mathrm{LB}=0.2$ and 0.5 is the one whose service levels are 1.0. While for $\mathrm{LB}=0.8$, the solution with service levels of 0.7 is the best. Moreover, similar to the confidence levels, the decision-makers can also select a suitable solution based on the sensitivity analysis if minimum service levels accepted by them can be decided.

To explore the reasons that result in Figs. 14 and 15, we calculate the three sub costs in the economic objective for each LB under different service levels. We find that the travel costs and loading and unloading operation costs are constant. The 
Fig. 15 Sensitivity of the environmental objective with respect to the service levels
Fig. 16 Sensitivity of the in-transit inventory costs with respect to the service levels
Environmental objective values in $\mathbf{~ k g}$

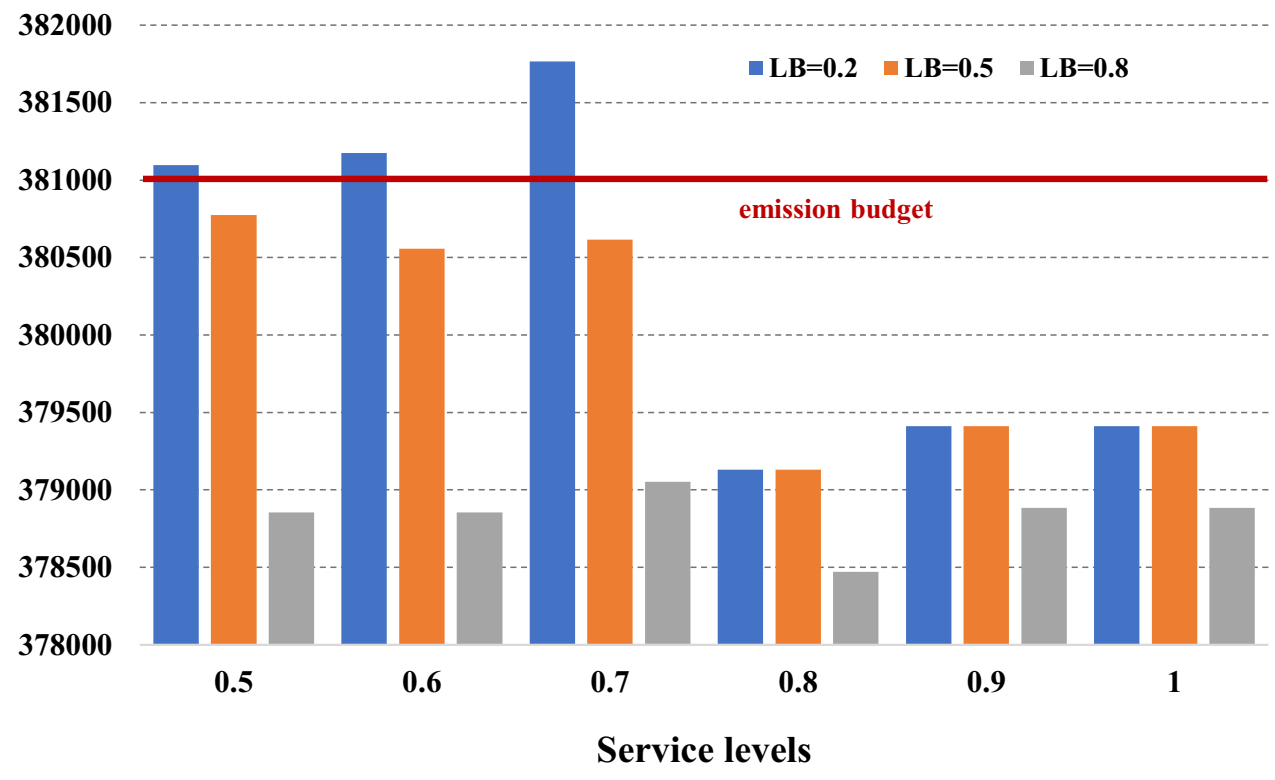

In-transit inventroy costs in CNY

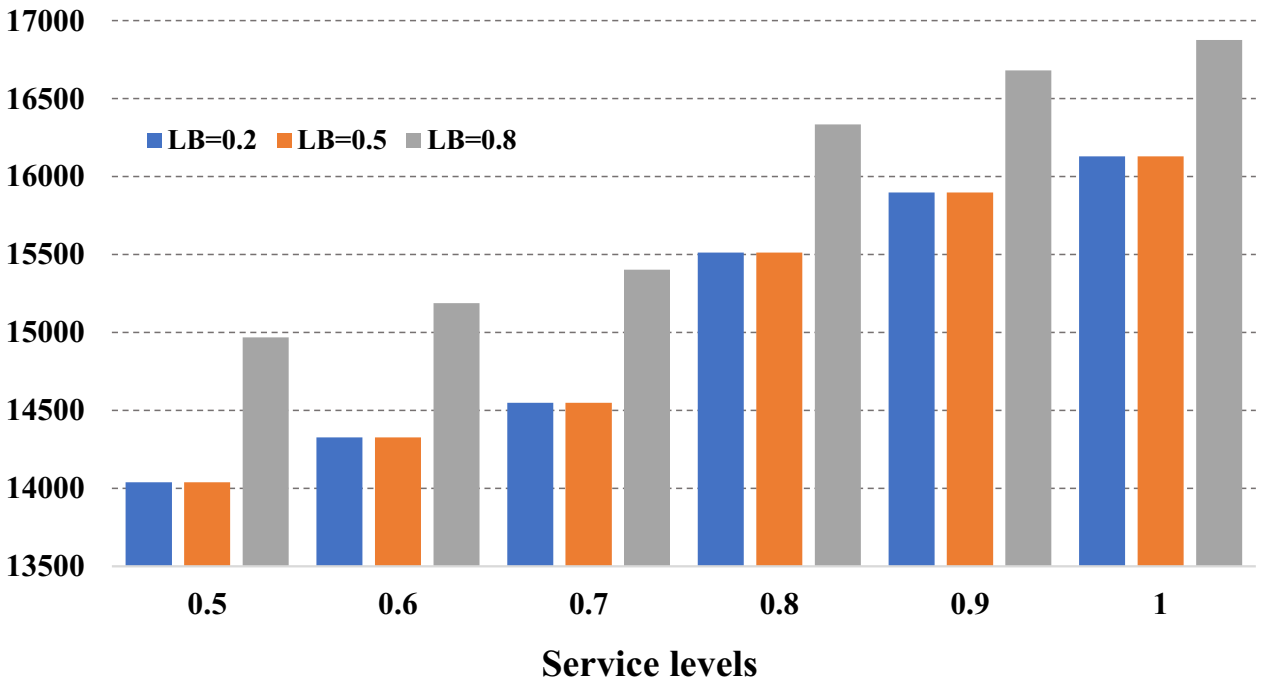

former remains $2379610 \mathrm{CNY}$, and the latter is $111230 \mathrm{CNY}$ for all the situations. As explained in "Sensitivity analysis on the optimization results with respect to the confidence levels", the unchanged travel costs indicate that the transportation services are the same. However, unlike the above two costs, the in-transit inventory costs are sensitive to the service levels, which can be seen in Fig. 16. In other words, the truck departure time planning for road services is sensitive to the service levels.

According to Fig. 16, we can conclude that the truck departure time planning for road services considering their travel time variation in different periods of the planning horizon is the essential way to enhance the service levels of the routing optimization. However, this way may lead to the waiting of containers at nodes, which increases the in-transit inventory costs and further contributes to the increase of the economic objective values.

\section{Conclusions}

This study investigates a green road-rail intermodal routing problem with improved pickup and delivery services under uncertainty. We make the following contributions in this study to enhance the environmental sustainability, timeliness, and feasibility of the problem optimization. 
(1) A road-rail intermodal routing problem is explored from a multi-objective optimization perspective, in which minimizing carbon dioxide emissions is considered to address the environmental concerns of the routing, optimizing the service levels of pickups and deliveries is formulated to enhance its timeliness, and modeling uncertainty is incorporated to enhance its feasibility.

(2) Besides formulating schedule-based rail services, this study considers the time flexibility of road services, and focuses on modeling the truck departure time planning for road services in which their travel times and emission factors vary in different periods of the planning horizon. The above modeling of road services provides a helpful option to help decision-makers to reduce emissions and improve service levels.

(3) Multiple sources of uncertainty in the transportation system, including the travel times and carbon dioxide emission factors of road services in various periods of the planning horizon and the capacities of rail services, are comprehensively considered to improve the feasibility of the optimization.

(4) A FMOMINLP model is developed for the problem, and credibility-based FCCP and linearization method are adopted to generate a crisp equivalent MOMILP model. An interactive fuzzy programming approach with the BOF method is designed to obtain the Pareto solutions to the problem.

Based on an empirical study oriented on the Chinese scenario, the optimization results and sensitivity analysis reveal the following managerial insights that can help decisionmakers to better organize the transportation by routing optimization.

(1) The economic objective of minimizing costs and environmental objective of minimizing carbon dioxide emissions are in conflict with each other. Trade-offs between the two objectives can be effectively made by the decision-makers based on the Pareto solutions obtained by the interactive fuzzy solution approach.

(2) Improving the confidence levels of uncertainty to achieve higher feasibility of routing optimization worsens both economic and environmental objectives, while improving the service levels of pickups and deliveries generally improve the environmental objective, although still worsening the economic objective.

(3) Sensitivity of the routing optimization with respect to the confidence levels and service levels enables the decision-makers to flexibly select the most suitable solution when they determine the objective budgets or have preferences on minimum feasibility degrees or service levels.
(4) Considering the variation of both travel times and emission factors of road services in different periods of the planning horizon, the truck departure time planning for road services plays an essential role in improving the environmental sustainability and service level of the routing optimization.

Future works can explore the design of intelligent algorithms to solve the large-scale road-rail intermodal routing problem in a more efficient way, since the problem is proved to be NP-hard [17]. Furthermore, many other fuzzy programming approaches to address the routing problem under uncertainty can be also employed and their performances can be compared in the future. Another direction is to extend the problem by considering disruptions on the schedules of rail services.

Supplementary Information The online version contains supplementary material available at https://doi.org/10.1007/s40747-021-00598-1.

Funding This study was funded by the Shandong Provincial Natural Science Foundation of China under Grant No. ZR2019BG006, the Project for Humanities and Social Sciences Research of Ministry of Education of China under Grant No. 19YJC630149, and the Shandong Provincial Higher Educational Social Science Program of China under Grant No. J18RA053.

\section{Declarations}

Conflict of interest On behalf of all authors, the corresponding authors state that there is no conflict of interest.

Open Access This article is licensed under a Creative Commons Attribution 4.0 International License, which permits use, sharing, adaptation, distribution and reproduction in any medium or format, as long as you give appropriate credit to the original author(s) and the source, provide a link to the Creative Commons licence, and indicate if changes were made. The images or other third party material in this article are included in the article's Creative Commons licence, unless indicated otherwise in a credit line to the material. If material is not included in the article's Creative Commons licence and your intended use is not permitted by statutory regulation or exceeds the permitted use, you will need to obtain permission directly from the copyright holder. To view a copy of this licence, visit http://creativecomm ons.org/licenses/by/4.0/.

\section{References}

1. Hosseini S, Al-Khaled A (2021) Freight flow optimization to evaluate the criticality of intermodal surface transportation system infrastructures. Comput Ind Eng 159:107522

2. Zhang W, Wang X, Yang K (2020) Uncertain multi-objective optimization for the water-rail-road intermodal transport system with consideration of hub operation process using a memetic algorithm. Soft Comput 24(5):3695-3709 
3. Heinold A, Meisel F (2020) Emission limits and emission allocation schemes in intermodal freight transportation. Transp Res Part E Logist Transp Rev 141:101963

4. Heinold A, Meisel F (2019) Emission oriented vs. time oriented routing in the European intermodal rail/road freight transportation network. Logistics management. Springer, Cham, pp 188-202

5. Ke, G. Y., \& Verma, M. (2021). A framework to managing disruption risk in rail-truck intermodal transportation networks. Transportation Research Part E: Logistics and Transportation Review, 102340.

6. Kuzmicz KA, Pesch E (2019) Approaches to empty container repositioning problems in the context of Eurasian intermodal transportation. Omega 85:194-213

7. Elbert R, Müller JP, Rentschler J (2020) Tactical network planning and design in multimodal transportation-a systematic literature review. Res Transp Bus Manag 35:100462

8. Caris A, Macharis C, Janssens GK (2013) Decision support in intermodal transport: a new research agenda. Comput Ind 64(2): 105-112

9. Sun Y (2020) Fuzzy approaches and simulation-based reliability modeling to solve a road-rail intermodal routing problem with soft delivery time windows when demand and capacity are uncertain. Int J Fuzzy Syst 22(7):2119-2148

10. Chang TS (2008) Best routes selection in international intermodal networks. Comput Oper Res 35(9):2877-2891

11. Flodén J, Bärthel F, Sorkina E (2017) Transport buyers choice of transport service-a literature review of empirical results. Res Transp Bus Manag 100(23):35-45

12. Wang QZ, Chen JM, Tseng ML, Luan HM, Ali MH (2020) Modelling green multimodal transport route performance with witness simulation software. J Clean Prod 248:119245

13. Liu D, Ge YE (2018) Modeling assignment of quay cranes using queueing theory for minimizing $\mathrm{CO}_{2}$ emission at a container terminal. Transp Res Part D Transp Environ 61:140-151

14. De La Torre R, Corlu CG, Faulin J, Onggo BS, Juan AA (2021) Simulation, optimization, and machine learning in sustainable transportation systems: models and applications. Sustainability 13(3): 1551

15. Demir E, Hrušovský M, Jammernegg W, Van Woensel T (2019) Green intermodal freight transportation: bi-objective modelling and analysis. Int J Prod Res 57(19):6162-6180

16. Dua A, Sinha D (2019) Quality of multimodal freight transportation: a systematic literature review. World Rev Intermodal Transp Res 8(2):167-194

17. Ayar B, Yaman H (2012) An intermodal multicommodity routing problem with scheduled services. Comput Optim Appl 53(1):131-153

18. Wang Q, Nie X (2021) A stochastic programming model for emergency supply planning considering transportation network mitigation and traffic congestion. Soc Econ Plan Sci. https://doi. org/10.1016/j.seps.2021.101119

19. Gao X, Cao C (2020) Multi-commodity rebalancing and transportation planning considering traffic congestion and uncertainties in disaster response. Comput Ind Eng 149:106782

20. Sun Y, Zhang G, Hong Z, Dong K (2018) How uncertain information on service capacity influences the intermodal routing decision: a fuzzy programming perspective. Information 9(1):24

21. Uddin M, Huynh N (2019) Reliable routing of road-rail intermodal freight under uncertainty. Netw Spat Econ 19(3):929-952

22. Sun Y, Hrušovský M, Zhang C, Lang M (2018) A time-dependent fuzzy programming approach for the green multimodal routing problem with rail service capacity uncertainty and road traffic congestion. Complexity 2018:8645793

23. Delbart T, Molenbruch Y, Braekers K, Caris A (2021) Uncertainty in intermodal and synchromodal transport: review and future research directions. Sustainability 13(7):3980
24. Sun Y (2020) Green and reliable freight routing problem in the road-rail intermodal transportation network with uncertain parameters: a fuzzy goal programming approach. J Adv Transp 2020:7570686

25. Guo W, Atasoy B, van Blokland WB, Negenborn RR (2020) A global intermodal shipment matching problem under travel time uncertainty. In: International conference on computational logistics, Springer, Cham, pp 553-568

26. Zhang D, He R, Li S, Wang Z (2017) A multimodal logistics service network design with time windows and environmental concerns. PLoS ONE 12(9):e0185001

27. Wang W, Xu X, Jiang Y, Xu Y, Cao Z, Liu S (2020) Integrated scheduling of intermodal transportation with seaborne arrival uncertainty and carbon emission. Transp Res Part D Transp Environ $88: 102571$

28. Chang YT, Lee PTW, Kim HJ, Shin SH (2010) Optimization model for transportation of container cargoes considering short sea shipping and external cost: South Korean case. Transp Res Rec 2166(1):99-108

29. Vale C, Ribeiro IM (2018) Intermodal routing model for sustainable transport through multi-objective optimization. In: First international conference on intelligent transport systems, Springer, Cham, pp 144-154

30. Verma M, Verter V (2010) A lead-time based approach for planning rail-truck intermodal transportation of dangerous goods. Eur J Oper Res 202(3):696-706

31. Sun Y, Lang M (2015) Modeling the multicommodity multimodal routing problem with schedule-based services and carbon dioxide emission costs. Math Probl Eng 2015:406218

32. Demir E, Burgholzer W, Hrušovský M, Arıkan E, Jammernegg W, Van Woensel T (2016) A green intermodal service network design problem with travel time uncertainty. Transp Res Part B Methodol 93:789-807

33. Fazayeli S, Eydi A, Kamalabadi IN (2018) Location-routing problem in multimodal transportation network with time windows and fuzzy demands: presenting a two-part genetic algorithm. Comput Ind Eng 119:233-246

34. Zhao Y, Liu R, Zhang X, Whiteing A (2018) A chance-constrained stochastic approach to intermodal container routing problems. PLoS ONE 13(2):e0192275

35. Hrušovský M, Demir E, Jammernegg W, Van Woensel T (2018) Hybrid simulation and optimization approach for green intermodal transportation problem with travel time uncertainty. Flex Serv Manuf J 30(3):486-516

36. Wang S, Zhang Q, Wang W (2017) The impact of carbon abatement policies on port intermodal freight transportation routing and cost. In: International conference on electrical and information technologies for rail transportation, Springer, Singapore, pp 689-699

37. Guo W, Atasoy B, van Blokland WB, Negenborn RR (2020) A dynamic shipment matching problem in hinterland synchromodal transportation. Decis Support Syst 134:113289

38. Ziaei Z, Jabbarzadeh A (2021) A multi-objective robust optimization approach for green location-routing planning of multi-modal transportation systems under uncertainty. J Clean Prod 291:125293

39. Dragomir AG, Doerner KF (2020) Solution techniques for the intermodal pickup and delivery problem in two regions. Comput Oper Res 113:104808

40. Tang J, Pan Z, Fung RY, Lau H (2009) Vehicle routing problem with fuzzy time windows. Fuzzy Sets Syst 160(5):683-695

41. Zarandi MHF, Hemmati A, Davari S (2011) The multi-depot capacitated location-routing problem with fuzzy travel times. Expert Syst Appl 38(8):10075-10084

42. Wang R, Yang K, Yang L, Gao Z (2018) Modeling and optimization of a road-rail intermodal transport system under uncertain information. Eng Appl Artif Intell 72:423-436 
43. Hu H, Li X, Zhang Y, Shang C, Zhang S (2019) Multi-objective location-routing model for hazardous material logistics with traffic restriction constraint in inter-city roads. Comput Ind Eng 128:861-876

44. Yang K, Wang R, Yang L (2020) Fuzzy reliability-oriented optimization for the road-rail intermodal transport system using tabu search algorithm. J Intell Fuzzy Syst 38(3):3075-3091

45. Sun Y, Liang X, Li X, Zhang C (2019) A fuzzy programming method for modeling demand uncertainty in the capacitated roadrail multimodal routing problem with time windows. Symmetry 11(1):91

46. Ke GY (2020) Managing rail-truck intermodal transportation for hazardous materials with random yard disruptions. Ann Oper Res. https://doi.org/10.1007/s10479-020-03699-1

47. Chen SM (1996) Evaluating weapon systems using fuzzy arithmetic operations. Fuzzy Sets Syst 77(3):265-276

48. Liao CH, Tseng PH, Lu CS (2009) Comparing carbon dioxide emissions of trucking and intermodal container transport in Taiwan. Transp Res Part D Transp Environ 14(7):493-496

49. Khishtandar S (2019) Simulation based evolutionary algorithms for fuzzy chance-constrained biogas supply chain design. Appl Energy 236:183-195

50. Tirkolaee EB, Abbasian P, Weber GW (2021) Sustainable fuzzy multi-trip location-routing problem for medical waste management during the COVID-19 outbreak. Sci Total Environ 756:143607

51. Zaeimi MB, Rassafi AA (2021) Designing an integrated municipal solid waste management system using a fuzzy chance-constrained programming model considering economic and environmental aspects under uncertainty. Waste Manag 125:268-279

52. Tayyab M, Sarkar B (2021) An interactive fuzzy programming approach for a sustainable supplier selection under textile supply chain management. Comput Ind Eng 155:107164

53. Zahiri B, Pishvaee MS (2017) Blood supply chain network design considering blood group compatibility under uncertainty. Int J Prod Res 55(7):2013-2033

54. Kundu P, Kar S, Maiti M (2013) Multi-objective multi-item solid transportation problem in fuzzy environment. Appl Math Model 37(4):2028-2038

55. Nahmias S (1978) Fuzzy variables. Fuzzy Sets Syst 1(2):97-110

56. Zheng Y, Liu B (2006) Fuzzy vehicle routing model with credibility measure and its hybrid intelligent algorithm. Appl Math Comput 176(2):673-683

57. Cao E, Lai M (2009) A hybrid differential evolution algorithm to vehicle routing problem with fuzzy demands. J Comput Appl Math 231(1):302-310

58. Xu J, Zhou X (2013) Approximation based fuzzy multi-objective models with expected objectives and chance constraints: application to earth-rock work allocation. Inf Sci 238:75-95

59. Habib MS, Asghar O, Hussain A, Imran M, Mughal MP, Sarkar B (2021) A robust possibilistic programming approach toward animal fat-based biodiesel supply chain network design under uncertain environment. J Clean Prod 278:122403

60. Zhu H, Zhang J (2009) A credibility-based fuzzy programming model for APP problem. In: 2009 International conference on artificial intelligence and computational intelligence, vol 1, IEEE, pp $455-459$
61. Pishvaee MS, Razmi J, Torabi SA (2012) Robust possibilistic programming for socially responsible supply chain network design: a new approach. Fuzzy Sets Syst 206:1-20

62. Xie Y, Lu W, Wang W, Quadrifoglio L (2012) A multimodal location and routing model for hazardous materials transportation. J Hazard Mater 227:135-141

63. Resat HG, Turkay M (2019) A discrete-continuous optimization approach for the design and operation of synchromodal transportation networks. Comput Ind Eng 130:512-525

64. Zandkarimkhani S, Mina H, Biuki M, Govindan K (2020) A chance constrained fuzzy goal programming approach for perishable pharmaceutical supply chain network design. Ann Oper Res 295(1):425-452

65. Pishvaee MS, Razmi J (2012) Environmental supply chain network design using multi-objective fuzzy mathematical programming. Appl Math Model 36(8):3433-3446

66. Heidari-Fathian H, Pasandideh SHR (2018) Green-blood supply chain network design: robust optimization, bounded objective function and Lagrangian relaxation. Comput Ind Eng 122:95-105

67. Li Z, Liu Y, Yang Z (2021) An effective kernel search and dynamic programming hybrid heuristic for a multimodal transportation planning problem with order consolidation. Transp Res Part E Logistics Transp Rev 152:102408

68. Sun Y, Li X, Liang X, Zhang C (2019) A bi-objective fuzzy credibilistic chance-constrained programming approach for the hazardous materials road-rail multimodal routing problem under uncertainty and sustainability. Sustainability 11(9):2577

69. China State Railway Group Company. http://hyfw.95306.cn/ hyinfo/page/home-hyzx-index. Accessed 8 Aug 2021

70. Ministry of Transport. http://cyfd.cnki.com.cn/Article/ N2007030054000163.htm. Accessed 8 Aug 2021

71. Resat HG, Turkay M (2015) Design and operation of intermodal transportation network in the Marmara region of Turkey. Transp Res Part E Logistics Transp Rev 83:16-33

72. LINDO Systems Inc (1998) Lingo: user's guide. Lindo Systems Incorporated

Publisher's Note Springer Nature remains neutral with regard to jurisdictional claims in published maps and institutional affiliations. 